\title{
Infections Due to Acinetobacter baumannii in the ICU: Treatment Options
}

\author{
Joseph P. Lynch III, MD ${ }^{1}$ George G. Zhanel, PhD² \\ ${ }^{1}$ Division of Pulmonary, Critical Care Medicine, Allergy, and Clinical \\ Immunology, Department of Medicine, The David Geffen School of \\ Medicine at UCLA, Los Angeles, California \\ 2 Department of Medical Microbiology/Infectious Diseases, University \\ of Manitoba, Rady College of Medicine, Winnipeg, Manitoba, Canada \\ ${ }^{3}$ Division of Infectious Diseases, Department of Medicine, Loyola \\ University Medical Center, Maywood, Illinois
}

Nina M. Clark, MD³

Semin Respir Crit Care Med 2017;38:311-325.

\begin{abstract}
Address for correspondence Joseph P. Lynch III, MD, FCCP, FERS, Division of Pulmonary, Critical Care Medicine, Allergy, and Clinical Immunology, The David Geffen School of Medicine at UCLA, 10833 Le Conte Avenue, Room 37-131 CHS, Los Angeles, CA 90095

(e-mail: jplynch@mednet.ucla.edu).
\end{abstract}

\author{
Abstract \\ Keywords \\ - multidrug resistance \\ - antimicrobial \\ resistance \\ - Acinetobacter spp. \\ - Acinetobacter \\ baumannii \\ - plasmids \\ - clonal spread \\ - carbapenemases
}

Bacteria within the genus Acinetobacter (principally A. baumannii-calcoaceticus complex $[A B C])$ are gram-negative coccobacilli that may cause nosocomial infections in critically ill or debilitated patients (particularly ventilator-associated pneumonia and infections of the bloodstream, urinary tract, and wounds). Treatment of Acinetobacter infections is difficult, as Acinetobacter spp. are intrinsically resistant to multiple antimicrobial agents, and have a remarkable ability to acquire new resistance determinants via mechanisms that include plasmids, transposons, integrons, and resistance islands. Since the 1990s, global resistance to antimicrobials has escalated dramatically among ABC. Global spread of multidrug-resistant (MDR)-A. baumannii strains reflects dissemination of a few clones between hospitals, geographic regions, and continents; excessive use of antibiotics amplifies this spread. Many isolates are resistant to all antimicrobials except colistin (polymyxin E) and tigecycline, and some infections are untreatable with existing antimicrobial agents. Antimicrobial resistance poses a serious threat to treat or prevent infections due to $A B C$. Strategies to curtail environmental colonization with MDR-ABD will require aggressive infection control efforts and cohorting of infected patients. Thoughtful antibiotic strategies are essential to limit the spread of MDR-ABC. Optimal therapy will likely require combination antimicrobial therapy of existing antibiotics as well as development of novel antibiotic classes.

\section{Microbiology}

Bacteria within the genus Acinetobacter are encapsulated, non-lactose fermenting, oxidase-negative gram-negative coccobacilli that may cause infections in health care or community settings, particularly in patients with comorbidities or skin/soft-tissue injuries. ${ }^{1-3}$ More than 20 Acinetobacter species have been identified, ${ }^{1}$ but the vast majority of clinical infections are caused by organisms within the $A$. calcoaceticus-A. baumannii complex (ABC). ${ }^{1,4-6}$ This complex comprises four species; A. baumannii, A. nosocomialis, and $A$. pittii cause clinical infections in humans, whereas A. calcoaceticus is an environmental organism of negligible clinical significance. ${ }^{1}$ A. baumannii is the most common species in most regions; the prevalence of $A$. pittii and $A$. nosocomialis is higher in Southeast Asia and A. pittii may be more common in Scandinavian countries. ${ }^{6-8}$ A. baumannii has been associated with heightened mortality and a higher degree of antimicrobial resistance compared with other Acinetobacter spp. ${ }^{1,6,9}$

\section{Clinical Features}

Acinetobacter species (spp.) most frequently cause nosocomial infections in critically ill or debilitated patients, ${ }^{10,11}$ including ventilator-associated pneumonia (VAP), ${ }^{10,12-14}$ bloodstream infections (BSI), ${ }^{6,11,15}$ device-associated
Issue Theme Controversies and Evolving Concepts in Hospital-Acquired Pneumonia; Guest Editors: Jean Chastre, $\mathrm{MD}$, and Charles-Edouard Luyt, MD, PhD
Copyright (c) 2017 by Thieme Medical Publishers, Inc., 333 Seventh Avenue, New York, NY 10001, USA. Tel: +1(212) 584-4662.
DOI https://doi.org/ 10.1055/s-0037-1599225. ISSN 1069-3424. 
infections (DAI), ${ }^{16}$ wound or skin and soft-tissue infections (SSTI), ${ }^{1,17}$ burns, ${ }^{18,19}$ urinary tract infections (UTI), ${ }^{1}$ intraabdominal infections (IAI), ${ }^{17}$ and meningitis. ${ }^{1}$ Additionally, Acinetobacter spp. have been implicated in SSTI sustained during disasters, including earthquakes, ${ }^{20}$ tsunamis, $^{21}$ terrorist attacks, ${ }^{22}$ and combat injuries in Vietnam, ${ }^{23}$ Iraq and Afghanistan, ${ }^{24,25}$ Ukraine, $^{26}$ Lebanon, and Syria. ${ }^{1,27}$ Infections due to Acinetobacter spp. occur more frequently in subtropical or tropical regions; in temperate climates, infections are more common in the summer. ${ }^{1,24,28}$ Community-acquired pneumonia ( $C A P$ ) due to $A B C$ rarely occurs in temperate climates, but fulminant CAP, sometimes with septic shock, has been described in Asian-Pacific regions. ${ }^{2,3,29-31}$ Factors predisposing to ABC-associated CAP include alcoholism, ${ }^{32,33}$ diabetes mellitus, male gender, renal or pulmonary disease, cirrhosis, advanced age, smoking. 3,31

\section{Prognosis of Infections Due to $A$. Baumannii}

Mortality rates with VAP or BSI due to Acinetobacter spp. are 30 to $75 \%$; these high mortality rates in part reflect comorbidities and severity of illness. ${ }^{1,15,34-37}$ In the EPIC II study, a multinational study of 14,414 ICU patients, infection with $\mathrm{ABC}$ was independently associated with a greater risk for hospital death (odds ratio [OR]: $1.53, p<0.001$ ). ${ }^{38}$ Within the past three decades, resistance rates among $A B C$ have escalated globally. ${ }^{1}$ Emergence of multidrug-resistant (MDR) strains has undoubtedly contributed to mortality. Not surprisingly, inappropriate initial empiric antibiotic therapy (IET) for pneumonia or sepsis due to $\mathrm{ABC}$ has been associated with heightened mortality. ${ }^{39-41}$ In a recent retrospective review of 1,423 patients hospitalized with sepsis or pneumonia due to $A B C, 82.3 \%$ of isolates were MDR. ${ }^{40}$ MDR-ABC strongly predicted receipt of IET (OR: $5.5, p<0.001$ ) and IET was associated with higher hospital mortality (OR: 1.8, $p<0.001) .{ }^{40}$ In light of the rising incidence of MDR-ABC, ${ }^{42}$ a multinational consensus statement was recently published regarding the management and prevention of $A$. baumannii infections in the ICU. ${ }^{43}$

\section{Infections Due to ABC in the Hospital Setting}

\section{ICU Infections}

Most ABC infections occur in hospitalized patients in the ICU, often with multiple comorbidities. Device-related infections (DRI) are typical (i.e., VAP, central venous catheter [CVC]associated BSI, surgical site infections (SSI), catheter-associated UTIs). The EPIC II point prevalence study in 2007 comprising 75 countries implicated Acinetobacter spp. in $8.8 \%$ of all ICU infections, with rates of $19 \%$ in Asia and $17 \%$ in Eastern Europe. ${ }^{38}$ In the SENTRY study from January 2009 to December 2011, ABCs were implicated in $7 \%$ of ICU infections in the United States and Europe. ${ }^{44}$ Even higher rates of $A B C$ infections have been reported in Latin America $^{45,46}$ and Asia. ${ }^{17,47,48}$ In a review of Vietnamese pediatric ICUs, ABC was implicated in $18.4 \%$ of hospitalacquired infections (HAI); 65\% of isolates were carbapenem resistant (CPR). ${ }^{49}$ In a prospective study from six hospitals in Iran (2011-2012), ABC was implicated in 35\% of DRI among hospitalized adults. ${ }^{16}$ Importantly, $70.5 \%$ were CPR.

\section{Hospital-Acquired Pneumonia}

$\mathrm{ABC}$ is a common cause of ICU-acquired pneumonia, accounting for 8 to $14 \%$ of VAP in the United States ${ }^{50}$ and Europe, ${ }^{51}$ but much higher rates $(19 \%$ to $>50 \%)$ in Asia, ${ }^{48,52}$ Latin America, ${ }^{53}$ and some Middle Eastern ${ }^{54}$ countries. In the United States, rates of VAP due to ABC increased from $4 \%$ in 1986 to $7.0 \%$ in 2003; no increase was observed for any other gram-negative bacilli. ${ }^{55}$ Data from 463 hospitals in the United States from January 2006 to October 2007 implicated A. baumannii in $8.4 \%$ of VAP. ${ }^{50}$ In a study of 411 cases of VAP from nine European countries, A. baumannii was implicated in $13.9 \%$ of cases. ${ }^{51}$ In a cohort of 827 cases of VAP in 27 ICUs in Europe, A. baumannii was implicated in $11 \%$ of early-onset and $26.5 \%$ of late-onset VAP. ${ }^{56}$ In Greece and Turkey, ABC was the most common cause of VAP. ${ }^{56}$ One prospective study in Turkey implicated ABC in $54 \%$ of VAP. ${ }^{54}$ Rates of VAP due to $A B C$ are high in tropical or subtropical regions, particularly in Asia. In a series of 621 cases of VAP in Japan from 2005 to 2011 , Acinetobacter accounted for $54.3 \%$ of cases. ${ }^{52}$ A prospective study in 10 Asian countries from 2008 to 2009 of HAP in adults ( $n=2,554)$ implicated Acinetobacter spp. in $36.5 \%$ of cases. ${ }^{47}$ Importantly, $67.3 \%$ of Acinetobacter spp. isolates were resistant to imipenem. ${ }^{47}$

\section{Risk Factors for Colonization or Infection with Acinetobacter spp.}

In critically ill patients, Acinetobacter spp. may colonize the gastrointestinal (GI) tract, skin, and respiratory tract, and may cause serious infections. ${ }^{1,24}$ Risk factors for acquisition of Acinetobacter spp. include invasive procedures or devices, prolonged ICU stay, mechanical ventilation (MV), enteral feedings, burns, and recent use of broad-spectrum antibiotics, particularly cephalosporins (CEPHS) or fluoroquinolones (FQs) ${ }^{1,24,34,57,58}$ (-Table 1). A prospective study identified the following independent risk factors for ICU-acquired A. baumannii: (1) prior occupant in that room with $A$. baumannii (OR: 4.2, $p<0.001$ ) and (2) MV (OR: 9.3, $p<0.05) .{ }^{59}$ Diabetes mellitus may increase the risk of recurrent or persistent colonization with $A B C{ }^{60}$ Risk factors for $A B C$ bacteremia among ICU patients include colonization with $A B C$; high APACHE II scores; MV; presence of an endotracheal tube; recent invasive procedures; CVCs; and prior antimicrobials. ${ }^{1}$ In one study, colonization of CVCs with MDR-ABC was associated with a $28 \%$ risk of subsequent bacteremia. ${ }^{61}$ Studies in patients with malignancies cited the following risk factors for $A$. baumannii infection: CVC and nasogastric tubes, ${ }^{62}$ admission to the ICU, ${ }^{63}$ dialysis, and prolonged ICU stay ${ }^{64}$; hematological malignancies; use of cefepime; and use of total parenteral nutrition (TPN). ${ }^{57}$ In neonatal ICUs, low birth weight, TPN, and presence of CVCs were risk factors for bacteremias due to $\mathrm{ABC}$ compared with uninfected infants. ${ }^{65}$ 
Table 1 Risk factors for Acinetobacter acquisition or infection

\begin{tabular}{|l|l|}
\hline Risk factor & Reference \\
\hline Invasive procedures, devices & 62,65 \\
\hline ICU admission and/or prolonged stay & $1,64,67$ \\
\hline $\begin{array}{l}\text { Mechanical ventilation and duration } \\
\text { of mechanical ventilation }\end{array}$ & $59,64,67$ \\
\hline Nasogastric tube & 62 \\
\hline Receipt of broad-spectrum antibiotics & $57,62,64,67$ \\
\hline Receipt of fluconazole & 67 \\
\hline $\begin{array}{l}\text { Prior hospital room occupant } \\
\text { with A. baumannii }\end{array}$ & 59 \\
\hline Colonization with Acinetobacter & 1 \\
\hline Severity of illness score & 67 \\
\hline Dialysis & 64 \\
\hline Total parenteral nutrition & 57,65 \\
\hline Hematologic malignancy & 57 \\
\hline Exposure to contaminated fomites & $43,66,67$ \\
\hline Chronic pulmonary disease & 67 \\
\hline
\end{tabular}

Acinetobacter spp. are ubiquitous and may survive for prolonged periods on wet or dry surfaces. ${ }^{24,34}$ Contaminated environmental sources and transmission via medical personnel may cause outbreaks of nosocomial infections. ${ }^{43,66,67}$ Acquisition and spread of $\mathrm{ABC}$ has been noted in hospitals, ${ }^{66}$ rehabilitation centers, and long-term care facilities (LTCFs), among pilgrims returning from the Hajj (Makkah) ${ }^{68}$ and in the community (particularly among the elderly). ${ }^{1,2}$ Colonized or infected patients, selection pressure from antimicrobial use, and incomplete compliance with infection control procedures may facilitate persistence or spread of MDR-ABC within hospital or institutional settings. ${ }^{1,66}$ Removal or disinfection and sterilization of contaminated equipment (e.g., ventilator or nebulizer tubing) or fomites may eliminate the problem. ${ }^{24,66}$ An outbreak of MDR-ABC in a surgical ICU was linked to aerosolization of $A B C$ during pulsatile lavage of wounds. ${ }^{67}$ Multifaceted infection control measures led to control of the outbreak. Interestingly, additional risk factors for acquisition of MDR-ABC included receipt of fluconazole (OR: 73.3), receipt of levofloxacin (OR: 11.5), and chronic pulmonary disease (OR: 11.5$){ }^{67}$

\section{ABC Virulence Factors and Pathogenesis}

The virulence mechanisms and pathogenesis of A. baumannii infections have been reviewed elsewhere ${ }^{69,70} \mathrm{~A}$. baumannii has simple growth requirements and may survive in dry and desiccated conditions for prolonged periods ${ }^{1,69}$; further, $A$. baumannii is able to adhere to living or inert surfaces and form biofilms. ${ }^{1,2}$ Additional bacterial factors that may heighten survival and virulence include outer membrane porins, capsule, lipopolysaccharide, regulatory proteins, and iron acquisition systems. ${ }^{1,2,71}$

\section{Mechanisms of Antimicrobial Resistance}

Acinetobacter spp. have innate (chromosomal) resistance mechanisms against multiple antimicrobials but also can acquire new resistance determinants via mobile genetic elements such as plasmids, transposons, integrons, insertion sequences, and resistance islands. ${ }^{1-3,69,72-74}$ Mechanisms of antimicrobial resistance are numerous and include (1) enzymatic inactivation or modification of antimicrobials; (2) alteration in the bacterial target site(s); (3) permeability barriers to uptake of antimicrobials; (4) active efflux pumps (that extrude antibiotics from bacterial cells); (5) combinations of mechanisms, which may occur as the result of large genomic islands containing multiple resistance genes. ${ }^{1-3,70,72}$

\section{Global Escalation of Antimicrobial Resistance}

Within the past three decades, antimicrobial resistance rates among $A B C$ have escalated dramatically worldwide. ${ }^{17,72,75} \mathrm{In}$ some countries, more than $90 \%$ of ABCs are MDR. ${ }^{17}$ Molecular-based strain typing by pulse field gel electrophoresis (PFGE) or multilocus sequence typing (MLS) methods has documented global spread of MDR "epidemic clones" between hospitals, regions, and continents. ${ }^{72}$ International spread has been extensively documented: for example, between Brazil and Argentina ${ }^{76}$; from Iraq to Germany and the United States among military personnel ${ }^{77,78}$; from northwestern Europe to the Czech Republic and globally ${ }^{79}$; from Turkey to Europe, the Middle East, and the rest of $\mathrm{Asia}^{80}$; from southern to northern Europe, the Middle East, rest of Asia, and Latin America ${ }^{81}$; from Europe to multiple continents. ${ }^{34}$ The rate of increase may be amplified by selection pressure from antimicrobial use, crowding, lack of hygiene, and increased worldwide travel. ${ }^{24,34}$

\section{Impact of Antimicrobial Use on Antimicrobial Resistance}

Not surprisingly, the use of broad-spectrum antimicrobials has been linked to emergence of antimicrobial resistance. In the early 1990s, the use of imipenem against cephalosporin-resistant Klebsiella pneumoniae was associated with emergence of imipenem-resistant $A B C$ in one New York hospital. ${ }^{82}$ Further, in multiple hospitals in Brooklyn, New York, there was an association between the use of third-generation CEPHS and aztreonam and CP-resistant $A B C .{ }^{83}$ In one case-control study in a surgical ICU, risk factors for acquisition of imipenem-resistant (IR) and imipenem-susceptible (IS) strains of A. baumannii were assessed ${ }^{84}$ Risk factors for IR-ABC were ICU stay (OR: 21.5), prior exposure to imipenem (OR: 9.2), and prior exposure to third-generation CEPHS (OR: 2.1). Risk factors for IS-ABC include ICU stay (OR: 8.1) and prior exposure to third-generation CEPHS (OR: 2.1). Regionally and globally, selection pressure is the key determinant of emergence of CPR or MDR-ABC. 


\section{Resistance to $\beta$-Lactams}

\section{B-Lactamases}

All A. baumannii strains possess a chromosomal AmpC cephalosporinase that confers resistance to penicillins and early-generation cephalosporins (CEPHS); however, under normal circumstances, resistance to third- and fourthgeneration CEPHS due to AmpC is clinically insignificant. ${ }^{24,85}$ Clinically significant resistance may develop via hyperproduction of the AmpC cephalosporinase, ${ }^{85}$ the presence of insertion sequences that promote $\beta$-lactamase activity, ${ }^{46}$ or incorporation of mobile resistance genes. ${ }^{86}$

$\beta$-Lactamases are categorized based on molecular structure into groups $\mathrm{A}$ through $\mathrm{D}$ and functionally into three groups (1-3) based on the target enzyme they degrade. ${ }^{87,88}$ Group 1 (class C) cephalosporinases are relatively narrow spectrum. Group 2 (classes A and D) include serine $\beta$-lactamases and extended-spectrum $\beta$-lactamases (ESBLs) and have a broader spectrum of activity. ${ }^{88}$ Group 3 enzymes include metallo $\beta$ lactamases (class B), which are potent hydrolyzers of CP and are not inhibited by $\beta$-lactamase inhibitors. ${ }^{88} \beta$-Lactamases of the IMP, VIM, SIM, and NDM-1 families fall within Group 3. ${ }^{74}$

\section{Extended-Spectrum $\beta$-Lactamases}

Numerous extended-spectrum $\beta$-lactamases (ESBLs) including SHV, TEM, PER, VEB, GES, and CTX-M confer high-grade resistance to all CEPHS. ${ }^{1,34}$ ESBL clones (TEM or SHV) were initially described in Enterobacteriaceae in France and Belgium in the late 1980 s and mid-1990s, ${ }^{89,90}$ and rapidly spread globally. ${ }^{91}$ By the late 1990 s, other plasmid-encoded ESBLs (e.g., PER-1, VEB, CTX-M, and GES) were described among Enterobacteriaceae ${ }^{91}$ and less commonly among $P$. aeruginosa and Acinetobacter spp. ${ }^{34}$ ESBL-containing plasmids (PER-1 type) among A. baumannii (as well as P. aeruginosa, and Klebsiella spp.) were first recognized in the late 1990s in Turkey ${ }^{80}$ and France ${ }^{92}$ and spread globally. ${ }^{34}$ Clusters of $A B C$ infections due to VEB- 1 type ESBL were noted among French hospitals in 2003. ${ }^{93}$ Rapid clonal spread to Belgium, ${ }^{94}$ Argentina, ${ }^{95}$ Lebanon, ${ }^{34}$ and globally ${ }^{34}$ ensued. Other ESBLs identified in ABC include TEM-92 and -116 from Italy and the Netherlands, respectively; SHV-12 from China and the Netherlands, CTX-M-2 and CTX-M-43 from Japan and Bolivia, respectively. ${ }^{4}$ Later, CTX-M ESBLs were detected in India, ${ }^{96}$ Haiti, ${ }^{97}$ Brazil, ${ }^{98}$ and globally.

\section{Carbapenemases}

Many $\beta$-lactamases (including ESBLs) may also have hydrolytic activity against $\mathrm{CPs}$ via production of carbapenamases (CPE). The emergence of carbapenemases has created a major "hole" in antibiotic coverage against ABC. Carbapenemases include group 2 class D oxacillinases (e.g., OXA enzymes) and class B metallo- $\beta$-lactamases (MBLs) (e.g., IMP, VIM, and SIM-1 groups) ${ }^{34,85}$ and the newer CPE (i.e., KPC-like; GES-like, ${ }^{99-102}$ New Delhi metallo- $\beta$-lactamase-1 [NDM-1]). ${ }^{1,69,103,104}$

\section{Class D Serine Carbapenemases}

Globally, the most common CPE in A. baumannii are the class D serine oxacillinases (OXA), represented by the OXA-23-,
OXA-24-, OXA-58-, and OXA-143-like types that can be encoded on chromosomes or plasmids. ${ }^{1,46,105-107}$ The first CPE (an OXA-type enzyme) in ABC was discovered in Scotland $1985 .{ }^{108}$ By the mid-1990s, CPR-ABC clones (principally OXA-type CPE) were noted in Latin America, ${ }^{46,109}$ the United Kingdom (UK), ${ }^{110,111}$ Europe, ${ }^{1,34,105}$ North America, ${ }^{1,34}$ Australia, ${ }^{1}$ Africa, the Middle East, and Asia. ${ }^{112}$ In 2003, the OXA-58 oxacillinase (bla OXA-58 $_{2}$ gene) was isolated from a CPR-Acinetobacter strain in Toulouse, France. ${ }^{105}$ Subsequently, OXA-58-producing CPR-ABC strains were reported in other Mediterranean countries (e.g., Lebanon, Turkey) ${ }^{34}$ and China. ${ }^{113}$ After 2009, ABC-producing OXA-23 (bla $a_{\text {OXA-23 }}$ gene) became the dominant OXA in Europe, ${ }^{114}$ United States, ${ }^{115}$ Latin America, ${ }^{106}$ and globally. ${ }^{69,116}$ Three clonal lineages (known as Worldwide Clones 1, 2, and 3) dominate among clinical isolates of MDR-ABC globally. ${ }^{1,34}$

KPC, a CPE, first reported in 1996 in K. pneumoniae in North Carolina, ${ }^{117}$ spreads rapidly within the northeastern United States ${ }^{118}$ and to France, ${ }^{119}$ Israel, Greece, Italy, ${ }^{120}$ and globally. ${ }^{91} \mathrm{KPC}$ is encoded on plasmids in Enterobacteriaceae and $P$. aeruginosa, ${ }^{119,121}$ but has not widely disseminated among ABC. KPC-producing ABCs were detected in 10 isolates of $A$. baumannii in Puerto Rico in $2010 .{ }^{122}$ To our knowledge, KPCproducing $\mathrm{ABC}$ s have not been reported in other countries. ${ }^{121}$

A newer group of CPEs termed GES (Guiana extendedspectrum $\beta$ - lactamases) was first identified in K. pneumoniae in 2000, and later reported in Acinetobacter spp. in France in $2009^{123}$ followed by rapid spread to Belgium, ${ }^{100}$ the Middle East, and Northern Africa. ${ }^{99,101,102,124-126}$

A novel CPE, termed NDM-1, was first detected in a $K$. pneumoniae isolate in a Swedish patient transferred from India. ${ }^{103}$ Retrospective studies showed that NDM- 1 had been endemic among K. pneumoniae and Escherichia coli in Indian hospitals since 2006. ${ }^{127}$ By 2010, NDM-1-producing Enterobacteriaceae had been found on five continents and linked to travel in India or Pakistan. ${ }^{128}$ In the United States, three cases of infections due to NDM-1-producing Enterobacteriaceae were reported in 2010; all three had recently received medical care in India. ${ }^{129}$ From 2010 on, numerous publications cited NDM-1-producing ABC in Europe, ${ }^{72,126,130-134}$ the Middle East, ${ }^{135-138}$ Africa, ${ }^{132,139-144}$ Asia. ${ }^{145-149}$ Epidemiological reviews suggest that the majority of infections due to NDM-1-producing ABC occur in India, Asia, the Middle East, and the Balkans. ${ }^{104}$ Berrazeg et al reviewed all publications of infections due to NDM-1-producing bacteria from 2009 to December 31, 2012, and identified 950 cases. $^{104}$ Only 36 cases (3.8\%) were due to ABC. Although infections due to NDM-1-producing $A B C$ have been cited in Brazil, ${ }^{150}$ Paraguay, ${ }^{151}$ Argentina, ${ }^{152}$ and Honduras, ${ }^{153}$ NDM1-producing $A B C$ appears to be rare in the Americas.

\section{Epidemiology and History of Antimicrobial Resistance among Acinetobacter spp.}

In the 1970s, Acinetobacter spp. were usually susceptible to ampicillin, cephalosporins, carbapenems (CPs), and several antibiotic classes. ${ }^{1}$ By the 1980 s, resistance to various classes of antibiotics appeared, but nearly all isolates remained 
susceptible to CPs. In the early 1990s, carbapenem-resistant (CPR) strains emerged. ${ }^{1}$ Importantly, CPR-ABCs are often resistant to all classes of antimicrobials except colistin and tigecycline. ${ }^{1,34}$ Ominously, strains of Acinetobacter resistant to colistin and tigecycline have been reported. ${ }^{154,155}$ Drug resistance has an adverse impact on clinical outcomes. Compared with patients with CP-susceptible strains, patients with CPR-ABC infections have increased mortality and increased hospital and ICU length of stay. ${ }^{1}$

In the United States (and globally), CPR-ABCs have escalated dramatically over the past two decades. In the National Nosocomial Infections Surveillance (NNIS) System, CPR-ABC (ICU isolates) in the United States increased from 0\% in 1986 to $20 \%$ in $2002 .^{55}$ In a survey of more than 300 hospitals in the United States, CPR-A. baumannii increased from $9 \%$ in 1995 to $40 \%$ in $2004 .^{24}$ The MYSTIC Study surveyed changes in antimicrobial resistance from clinical isolates from 15 U.S. hospitals over a decade; resistance to imipenem increased from $10 \%$ in 1999 to $48 \%$ in 2008 . $^{156}$ The Surveillance Network (TSN) database examined more than 55,000 isolates of Acinetobacter spp. in the United States from 2002 to 2008; CPR increased from $20.6 \%$ in 2002 to $49.2 \%$ in $2008 .^{157} \mathrm{~A}$ survey of nine regions in the United States from 2005 to 2011 found that $30 \%$ of 2,900 isolates of $A B C$ were MDR. ${ }^{158}$ Another study in the United States in 2010 noted that 50\% of 514 clinical isolates of ABC were CPR. ${ }^{159}$ In the SENTRY study from 2009 to 2011 , susceptibility rates to imipenem in the United States were 43\% (ICU) and 63\% (non-ICU) and in Europe $45 \%$ (ICU) and 56\% (non-ICU). ${ }^{44}$

Worldwide, rates of CPR-ABC have been highest in Greece, Taiwan, and Latin America, 46,106,160-162 but remarkable differences between countries have been noted. ${ }^{17,163} \mathrm{~A}$ survey of 48 European hospitals (MYSTIC) in 2006 cited CPR in $42.5 \%$ of ABC clinical isolates. ${ }^{164}$ In the COMPACT study from 2008 to 2009 in Europe, the Middle East, and Africa, $49 \%$ of $\mathrm{ABC}$ isolates were resistant to imipenem. ${ }^{163}$ Resistance rates were higher in Turkey, Greece, Italy, Spain, and England (45-85\%) compared with France, Germany, and Sweden (4-20\%). ${ }^{163}$ In one tertiary care hospital in the United Kingdom, CPR among ABC bloodstream isolates (BSI) rose from $0 \%$ in 1998 to $55 \%$ in $2006 .{ }^{111}$ A survey of 11 countries in Latin America in 2011 found that more than $50 \%$ of $A B C$ clinical isolates were CPR. ${ }^{160}$ In the SENTRY study of $A B C$ isolates from 2006 to 2009, global CPR rates rose from $34.6 \%$ in 2006 to $59.8 \%$ in $2009 .^{165}$ The SMART surveillance study of urinary tract and IAI ABC isolates from 48 countries from 2011 to 2014 cited MDR ranging from 47\% in North America to more than 93\% in Europe and the Middle East. ${ }^{17}$ In China, 58\% of blood stream isolates of $A B C$ in 2013 were CPR. ${ }^{112}$ The SMART surveillance study, comprising 48 countries from 2001 to 2014, evaluated CPR resistance among ABC isolates from intra-abdominal and UTI. ${ }^{17}$ The incidence of MDR-ABC was lowest in North America (47\%) and ranged from 77 to $87 \%$ in Africa, Asia, and Latin America, and exceeded 93\% in Europe and the Middle East. ${ }^{17}$ This extraordinary rate of $C P R-A B C$ reflects selection pressure from antibiotic usage. The use of $C P$ s has been associated with increased incidence of $\mathrm{CPR}-\mathrm{ABC} .^{162,166}$ In one study, the prevalence of infections due to MDR-ABC fell 2.24-fold after implementing a policy of restricting CP use in the ICU. ${ }^{167}$

\section{Treatment of Infections Due to Acinetobacter spp.}

Nosocomial infections due to $\mathrm{ABC}$ have been associated with high mortality rates (particularly with BSI or VAP). ${ }^{24,34,35}$ Early appropriate antimicrobial therapy is critical. ${ }^{3,11,35}$ Optimal therapy for serious $A B C$ infections has not been established, ${ }^{1}$ as prospective randomized trials have not been done. For BSI, removal of invasive devices within 48 hours may reduce mortality. ${ }^{11}$ For SSTI or SSIs, debridement is an essential part of therapy. ${ }^{24}$ Carbapenems, alone or combined with a second agent, has been considered the best therapy for $A B C$ infections. ${ }^{1,34}$ However, the emergence of CPR strains limits the use of these agents as monotherapy for empirical treatment when CPR is a consideration. We believe a combination of a carbapenem plus colistin is appropriate as initial empirical therapy for serious $A$. baumannii infections when CPR is suspected. ${ }^{43}$ Other agents (e.g., $\beta$-lactam $/ \beta$-lactamase inhibitors, ceftazidime, or FQs) may be used, provided isolates are susceptible.

\section{Advanced Generation Cephalosporins}

Third- and fourth-generation cephalosporins (e.g., ceftazidime, cefepime) are not reliable for empirical treatment of infections due to $A B C$. Globally, only 20 to $40 \%$ of $A B C$ s are susceptible to expanded spectrum CEPHS. ${ }^{17}$ CEPHS should not be used as empirical treatment for $A B C$ infections, but may be considered for susceptible strains.

\section{Sulbactam}

Among $\beta$-lactamase inhibitors, sulbactam has the greatest bactericidal activity against $\mathrm{ABC} .^{1}$ Ampicillin-sulbactam (A/S) (due to the sulbactam component) may be effective therapy for some strains of $A B C .^{168}$ High-dose A/S and extended time of infusion may enhance bactericidal activity. ${ }^{169}$ Clinical data supporting the use of sulbactam are limited to small series. ${ }^{168,170}$ Sulbactam may display synergy against $A B C$ when combined with other antibiotics (e.g., CP, colistin). ${ }^{171}$

\section{Fluoroquinolones}

Fluoroquinolones may be active against some strains of $A B C$, but globally, fewer than $30 \%$ of ABCs are susceptible to FQs. ${ }^{17}$ $\mathrm{FQ}$ resistance can emerge via mutations in the quinolone resistance determining regions (QRDR) of gyrA and parC genes and/or by overexpression of efflux pumps. ${ }^{69}$

\section{Aminoglycosides}

Aminoglycoside resistance among ABCs may emerge via the production of aminoglycoside-modifying enzymes, 16S ribosomal RNA methyltransferase (ArmA), or efflux pumps. ${ }^{1}$ In one French study, increased use of amikacin was associated with emergence of amikacin-resistant $\mathrm{ABC}$; decreased amikacin use led to a decrease in case incidence. ${ }^{172}$ The 
activity of aminoglycosides against $\mathrm{ABC}$ is variable, but resistance rates exceed $60 \%$ in most countries. ${ }^{173}$ See - Table 2 for summary of antimicrobial resistance mechanisms among Acinetobacter spp.

\section{Treatment of Infections Due to Acinetobacter spp.}

In view of the high incidence of MDR-ABC, initial empirical therapy with combination therapy (typically CP plus colistin) is often employed while awaiting antimicrobial susceptibility results. Optimal therapy is not clear, as randomized, controlled studies are lacking. In the next sections, we will discuss antibiotics that are often used either as monotherapy or part of combination therapy for MDR-ABC.

\section{Polymyxins (Colistin)}

Polymyxins (e.g., polymyxin B and polymyxin E [colistin]) are cationic lipopeptides that disrupt the outer membrane of gram-negative bacteria and are rapidly bactericidal. ${ }^{155}$ Polymyxins are usually highly active against MDR-ABC, including isolates resistant to tigecycline. ${ }^{1}$ Colistin is administered intravenously as an inactive prodrug (colistimethate sodium [CMS]), whereas polymyxin B is an active drug. CMS is widely available, whereas polymyxin B is infrequently used. Resistance rates to colistin are generally low $(<1 \%),{ }^{174}$ but colistin resistance among $A B C s$ has been increasing. ${ }^{155,175}$ In a survey of $514 \mathrm{ABC}$ isolates from 65 sites in the United States and Puerto Rico in $2010,5 \%$ of isolates were resistant to colistin. ${ }^{159}$
Colistin can be administered by intravenous (IV) or inhaled routes. ${ }^{1}$ IV colistin has potential renal toxicity ${ }^{1}$ and neurotoxicity (principally paresthesias). ${ }^{1}$ Risk factors for nephrotoxicity include colistin dose $>5 \mathrm{mg} / \mathrm{kg} /$ day ideal body weight ${ }^{176}$ and concomitant use of rifampicin or nephrotoxins. ${ }^{176}$ Optimal dosing regimens for IV colistin have not been established. ${ }^{1,177}$ Colistin exhibits a concentrationdependent bactericidal activity; therapeutic effect depends on the ratio of peak serum concentration to minimum inhibitory concentration (MIC) or the ratio of the area under the curve (AUC) to MIC. ${ }^{1}$ Strategies involving higher doses, longer dosing intervals, loading doses, extended infusions, and pharmacokinetic/pharmacodynamic (PK/PD) principles have been proposed to optimize efficacy and prevent the development of resistance. ${ }^{178-180}$ However, colistin has relatively poor PK/PD properties, and it may be difficult to achieve high enough serum concentrations quickly. ${ }^{155} \mathrm{CMS}$ (a prodrug) has to be converted to the active form (colistin) in the plasma, and concentrations may be suboptimal for 2 to 3 days until a steady state is achieved; thus, a loading dose is recommended. ${ }^{1}$ One in vitro study suggested that achievement of serum levels more than $1 \mathrm{mg} / \mathrm{L}$ within 1 hour had significant bactericidal activity. ${ }^{181}$

Studies reporting efficacy of colistin monotherapy for ABC infections are limited. In a prospective study of 35 episodes of VAP due to MDR-ABC, patients were treated with imipenem $(n=14)$ versus colistin $(n=21)$ based on susceptibility testing. ${ }^{182}$ Cure rates were $57 \%$ in both groups; in-hospital mortality rates were similar (64 and 62\%, respectively). The

Table 2 Common mechanisms of antimicrobial resistance in Acinetobacter spp.

\begin{tabular}{|c|c|c|}
\hline Resistance mechanism & Target antimicrobial & References \\
\hline \multicolumn{3}{|l|}{ Enzymatic inactivation or modification of antimicrobials } \\
\hline AmpC $\beta$-lactamase with upstream insertion of ISAba1 & Cephalosporins & $1,46,70$ \\
\hline Non-carbapenemase oxacillinases (OXA) & Penicillins, cephalosporins & $1,18,45,68,70$ \\
\hline Metallo- $\beta$-lactamases (IMP, VIM, SIM, NDM-1) & $\begin{array}{l}\text { Penicillins, cephalosporins, } \\
\text { carbapenems }\end{array}$ & $1,103,124,130,135,145,150,153$ \\
\hline Non-metallo- $\beta$-lactamase carbapenemases (OXA, KPC) & $\begin{array}{l}\text { Penicillins, cephalosporins, } \\
\text { carbapenems, monobactams }\end{array}$ & $1,70,122$ \\
\hline $\begin{array}{l}\text { Extended-spectrum } \beta \text { - lactamases } \\
\text { (SHV, TEM, PER, VEB, GES, CTX-M) }\end{array}$ & $\begin{array}{l}\text { Penicillins, cephalosporins, } \\
\text { monobactams }\end{array}$ & $1,70,99,101,102,123-125$ \\
\hline Aminoglycoside-modifying enzymes (AAC, APH, AAD) & Aminoglycosides & 1,70 \\
\hline \multicolumn{3}{|l|}{ Modification of drug target site } \\
\hline gyrA and parC mutations & Fluoroquinolones & $1,69,70$ \\
\hline Alteration of ribosomal-binding site (RmtB, ArmA) & Aminoglycosides & 1,70 \\
\hline $\begin{array}{l}\text { Altered lipid A of bacterial lipopolysaccharide } \\
\text { (PmrAB two-component system mutation) }\end{array}$ & Colistin & 1,70 \\
\hline Loss of lipopolysaccharide (mutated IpxA, IpxC, Ipx D) & Colistin & 1,70 \\
\hline \multicolumn{3}{|l|}{ Altered cell permeability } \\
\hline Porin/outer membrane protein loss & Carbapenems, aminoglycosides & 70 \\
\hline \multicolumn{3}{|l|}{ Efflux pumps } \\
\hline RND efflux pump (AdeABC, AdeFGH, Ade IJK, AbeM) & $\begin{array}{l}\text { Fluoroquinolones, } \beta \text {-lactams, } \\
\text { aminoglycosides, tetracyclines }\end{array}$ & 1,70 \\
\hline
\end{tabular}


impact of combination therapy has not been elucidated. Turkish investigators retrospectively assessed clinical outcomes in 250 patients with BSI due to extremely resistant ABC. ${ }^{183}$ Thirty-six patients received colistin monotherapy; 214 received colistin plus a second agent. All isolates were susceptible to colistin. In-hospital mortality was lower in the combination group compared with monotherapy group (52.3 vs. $72.2 \%, p=0.03$ ) and rate of microbiological eradication was higher in the combination therapy compared with monotherapy ( 79.9 vs. $55.6 \%, p=0.001$ ). By multivariate analysis, Pitt bacteremia score, age, and duration of ICU stay were independent predictors of 14-day mortality. An observational study of 28 Spanish hospitals assessed 30-day mortality rates among 101 patients with serious infections due to MDR-ABC. ${ }^{184}$ Pneumonia was present in $50.5 \%$. Sixtyeight patients received monotherapy (MT) (usually a CP or colistin); 33 received combination therapy (CT). Thirty-day mortality rates were similar (23.5\% for MT; $24.2 \%$ for CT; $p=0.94$ ). Another observational study reviewed 69 organ transplant recipients either colonized $(n=28)$ or infected $(n=41)$ with XDR A. baumannii. ${ }^{185}$ Among 41 patients with infections, 37 received antimicrobial therapy. Clinical success at 28 days was achieved in 18/37 (49\%), but clinical recurrence developed within 3 months in 8 of 18 (44\%) within 3 months. Further, colistin resistance developed in 5 of 14 patients. The use of combination therapy with colistin and a carbapenem was an independent predictor of survival. ${ }^{185}$ These various retrospective studies are inadequate to assess the role or benefit (if any) of combination therapy or the optimal agents to use for serious infections due to $A B C$.

Aerosolized (inhaled) colistin has been used in patients with cystic fibrosis and as adjunctive therapy for nosocomial pneumonia due to $\mathrm{ABC}$, but data are limited to nonrandomized, retrospective studies. ${ }^{1,186}$ One randomized open-label trial compared the efficacy of nebulized CMS (plus IV colistin) for 100 patients with gram-negative VAP, $60 \%$ of which were due to $A B C$. Microbiological outcome was better with nebulized plus IV therapy (60.9\%) compared with $38.2 \%$ among IV CMS only group $(p=-0.03)$. Importantly, clinical outcomes were similar ( 51.0 vs. $53.1 \%, p=0.94$ ). Further, there were more episodes of bronchospasm in the nebulized plus IV therapy group ( 7.8 vs. $2.0 \%$, respectively, $p=0.36$ ). The clinical benefit of nebulized CMS to treat VAP has not been established.

Resistance to colistin may develop. ${ }^{185}$ Plasmid-mediated resistance via mcr-1 gene among Enterobacteriaceae was first reported China, ${ }^{187}$ and human cases of E. coli or Enterobacteriaceae expressing $m c r-1$ were described shortly thereafter in Switzerland, ${ }^{188,189}$ Canada, ${ }^{190}$ and Singapore. ${ }^{191}$ The $m c r-1$ gene has not yet been identified in Acinetobacter spp., but it is feasible that in time, MDR Acinetobacter could acquire this resistance mechanism. Colistin heteroresistance may also occur. ${ }^{155}$ Colistin-resistant $\mathrm{ABC}$ s appear to have reduced fitness and less virulence, ${ }^{192}$ including a decreased ability to form biofilms. ${ }^{193}$

\section{Tigecycline}

Tigecycline, a semisynthetic derivative of minocycline, has excellent in vitro activity against MDR-ABC (including CPR strains). ${ }^{194,195}$ However, clinical studies assessing efficacy of tigecycline for serious ABC infections are limited. Favorable clinical responses have been cited with tigecycline (alone or in combination with colistin) in some patients with MDR$A B C$ infections, ${ }^{1,196}$ but large, randomized trials are lacking. In one retrospective study, 266 patients with XDR-ABC infections treated with tigecycline alone or combined with other agents (i.e., $\mathrm{CP}$, extended-spectrum $\mathrm{CEPH}$, or piperacillin-tazobactam) were compared with 120 patients who received imipenem plus sulbactam to treat XDR-ABC. ${ }^{197}$ All isolates were resistant to all antibiotics tested except tigecycline and colistin. Thirty-day mortality rates were similar (44.7 and $46.7 \%$ ) between the groups. A prospective multicenter phase III trial cited lower cure rates in patients with ABC-VAP treated with tigecycline (68\% cure) compared with imipenem $(78 \%$ cure $){ }^{198}$ Overall mortality rates were similar with tigecycline (14.2\%) and imipenem (12.2\%). A retrospective study of adults with pneumonia in the ICU due to MDR$\mathrm{ABC}$ matched 84 patients receiving tigecycline to 84 patients receiving colistin. ${ }^{199}$ Mortality was higher (60.7\%) among patients receiving tigecycline compared with colistin ( $44 \%$ mortality, $p=0.04$ ). This excess mortality was significant only for those with MIC greater than $2 \mu \mathrm{g} / \mathrm{mL}{ }^{199}$ Ye et al retrospectively analyzed 168 hospitalized ICU patients with pneumonia due to $A B C$ treated with either sulbactam or ampicillin/sulbactam $(n=84)$ to patients treated with tigecycline $(n=84) .{ }^{200}$ Clinical responses (66.7\% for each group) and mortality rates were similar (17.9\% with sulbactam, $25.0 \%$ with tigecycline; $p=0.26$ ). Microbiological eradication was achieved more often with sulbactam (63.5 vs. $33.3 \%$ ).

Tigecycline achieves low peak serum concentrations $(<0.8 \mathrm{mg} / \mathrm{L})$ after a standard $100 \mathrm{mg}$ loading dose, ${ }^{1}$ a concentration below the MIC of many ABC isolates. Resistance to tigecycline may develop even while on therapy, ${ }^{194}$ and persistence of infection (with or without resistance) may occur. ${ }^{1}$ Efficacy of tigecycline for BSI due to ABC therefore cannot be assured. Importantly, tigecycline has been associated with an increased risk of death when studied against comparator antibiotics, especially among patients with hospital-acquired pneumonia (HAP). ${ }^{201}$ Higher doses of tigecycline (75-100 mg twice daily) have been recommended by some investigators, ${ }^{43}$ but randomized trials have not been done. Given the aforementioned limitations, we do not recommend tigecycline monotherapy to treat serious $A B C$ infections.

\section{Eravacycline}

Eravacycline is a novel fluorocycline of the tetracycline class with broad-spectrum activity against gram-negative and gram-positive aerobic and anaerobic pathogens. ${ }^{202}$ Like tigecycline, eravacycline is not affected by many of the tetracycline-specific resistance mechanisms found in gram-negative bacteria, including acquired efflux systems and ribosomal protection. ${ }^{202}$ Eravacycline is two- to fourfold more active (reduced $\mathrm{MIC}_{90}$ ) than tigecycline versus $A$. baumannii. ${ }^{203}$ Whether this increased in vitro activity translates into greater clinical efficacy is not known. 


\section{Other Antimicrobial Agents}

\section{Rifampin}

Rifampin exhibits activity against MDR-ABC in vitro and in animal models. ${ }^{1}$ In animal models, the combination of rifampin plus colistin may confer additive or synergic bactericidal activity. ${ }^{1}$ However, in two randomized trials of serious MDR-ABC infections, the combination of rifampin plus colistin was no better than colistin alone. ${ }^{204,205}$ The role of rifampin as part of combination therapy has not been established.

\section{Other Combination Therapy Using Colistin}

Combination therapy has been studied to treat MDR-ABC, particularly with colistin as part of the combination. ${ }^{171,183-185,206}$ In vitro studies have shown that synergy may be achieved with combinations of colistin, carbapenems, and rifampicin, in both colistin-S and colistin-R strains of Acinetobacter spp. ${ }^{207,208}$ In a retrospective multicenter study, Batirel et al evaluated 250 BSIs due to extremely drug resistant (XDR)-ABC (all isolates were susceptible to colistin). ${ }^{183}$ Groups included colistin monotherapy $(n=36)$; colistin + CP $\quad(n=102) ; \quad$ colistin + sulbactam $(n=69)$; and colistin + other agents $(n=43)$. Complete response rates, 14-day and in-hospital survival, and microbiologic eradication were significantly higher in the combination group, but no differences could be seen between the various combinations. ${ }^{183}$ A multicenter prospective observational study in Spain of 101 patients with MDR-ABC infections demonstrated no significant difference in 30-day mortality between combination therapy with colistin versus monotherapy with various agents, predominantly a CP. ${ }^{184}$ Cheng et al prospectively studied 176 episodes of bacteremia due to XDR-A. baumannii in three hospitals in Taiwan. ${ }^{206}$ Among infections with tigecycline MIC $>2 \mathrm{mg} / \mathrm{L}$, combination therapy with colistin plus tigecycline was associated with significantly higher 14-day mortality and more breakthrough bacteremias compared with colistin plus CP. ${ }^{206}$

The addition of glycopeptides (agents with gram-positive activity) to colistin has displayed synergy against $A B C$ in vitro. ${ }^{155}$ However, clinical studies are limited, and data are conflicting. ${ }^{209,210}$

\section{Novel Agents}

It is obvious that new agents are needed to treat $A B C$ infections. Anti-GNB compounds that belong to old classes of agents such as $\beta$-lactams, CPs, FQs, and $\beta$-lactamase inhibitors are in development, as are novel classes. ${ }^{211-214}$ Ceftazidime/avibactam contains an older third-generation CEPH (i.e., ceftazidime), with avibactam, a synthetic non- $\beta$ lactam, $\beta$-lactamase inhibitor that inhibits the activities of Ambler class A and C $\beta$-lactamases and some Ambler class D enzymes. ${ }^{215-217}$ Limited data suggest that the addition of avibactam does not improve the activity of ceftazidime against Acinetobacter spp. ${ }^{215}$ Ceftolozane is a novel cephalosporin with a chemical structure similar to that of ceftazi- dime, with the exception of a modified side chain at the three-position of the cephem nucleus, which confers potent antipseudomonal activity. ${ }^{217,218}$ The addition of tazobactam extends the activity of ceftolozane to include most ESBL producers as well as some anaerobic species. ${ }^{218}$ Limited data suggest that ceftolozane/tazobactam is 8 - to 16 -fold more active than ceftazidime versus $A$. baumannii. 218 Whether this increased in vitro activity translates into greater clinical efficacy is not known.

Plazomicin is a next-generation aminoglycoside that was synthetically derived from sisomicin. ${ }^{219}$ Plazomicin demonstrates activity against both gram-negative and gram-positive bacterial pathogens, including isolates harboring all clinically relevant aminoglycoside-modifying enzymes. ${ }^{212,216,219}$ Limited data suggest that plazomicin demonstrates approximately eightfold more active than gentamicin versus $A$. baumannii. ${ }^{220}$ Whether this increased in vitro activity translates into greater clinical efficacy is not known.

Among the new classes of antimicrobials, bis-indole compounds inhibit DNA and RNA synthesis and some have had very good in vitro activity against MDR ABC. ${ }^{221}$ Applying structure-based drug design, pyrrolopyrimidine agents were developed that inhibit both of the bacterial topoisomerases (DNA gyrase and topoisomerase IV) of GNB including ABC, Pseudomonas aeruginosa, and E. coli. ${ }^{222}$ Antimicrobial peptides, naturally occurring molecules of the innate immune systems of all types of living organisms, are potential new treatments for MDR organisms. ${ }^{223}$ Some of these, including melittin, indolicidin, and mastoparan, exhibit activity against colistin-susceptible and colistin-resistant $A B C$ isolates in vitro. ${ }^{224}$

\section{Prevention}

Hospital outbreaks of Acinetobacter infections may reflect environmental contamination $24,66,225-227$ or carriage of $A$. baumannii on the hands of health care workers. ${ }^{66}$ Aggressive infection-control measures including identifying sources of transmission, ${ }^{67,225}$ environmental cleaning, contact precautions, and hand hygiene and isolating or cohorting infected and colonized patients ${ }^{66,228}$ may be critical to stop or prevent outbreaks. In one study, daily chlorhexidine baths in ICU patients reduced the development VAP due to Acinetobacter. $^{229}$

\section{Conclusion}

The dramatic global rise of antimicrobial resistance among $\mathrm{ABC}$ reflects acquisition of novel resistance elements and spread via a few international clones. Many isolates are resistant to all antimicrobials except colistin, and some infections are untreatable with existing agents. Novel approaches including combinations of agents and extended infusion times may be required to optimize therapy. Appropriate use of antimicrobials and infection-control measures are critical to minimize antimicrobial resistance. ${ }^{43,66}$ 


\section{References}

1 Doi Y, Murray GL, Peleg AY. Acinetobacter baumannii: evolution of antimicrobial resistance-treatment options. Semin Respir Crit Care Med 2015;36(1):85-98

2 Jones CL, Clancy M, Honnold C, et al. Fatal outbreak of an emerging clone of extensively drug-resistant Acinetobacter baumannii with enhanced virulence. Clin Infect Dis 2015;61(2): 145-154

3 Davis JS, McMillan M, Swaminathan A, et al. A 16-year prospective study of community-onset bacteremic Acinetobacter pneumonia: low mortality with appropriate initial empirical antibiotic protocols. Chest 2014;146(4):1038-1045

4 Peleg AY, Seifert H, Paterson DL. Acinetobacter baumannii: emergence of a successful pathogen. Clin Microbiol Rev 2008;21(3): 538-582

5 Abbott I, Cerqueira GM, Bhuiyan S, Peleg AY. Carbapenem resistance in Acinetobacter baumannii: laboratory challenges, mechanistic insights and therapeutic strategies. Expert Rev Anti Infect Ther 2013;11(4):395-409

6 Wisplinghoff $\mathrm{H}$, Paulus $\mathrm{T}$, Lugenheim $\mathrm{M}$, et al. Nosocomial bloodstream infections due to Acinetobacter baumannii, Acinetobacter pittii and Acinetobacter nosocomialis in the United States. J Infect 2012;64(3):282-290

7 Wang X, Chen T, Yu R, Lü X, Zong Z. Acinetobacter pittii and Acinetobacter nosocomialis among clinical isolates of the Acinetobacter calcoaceticus-baumannii complex in Sichuan, China. Diagn Microbiol Infect Dis 2013;76(3):392-395

8 Karah N, Haldorsen B, Hegstad K, Simonsen GS, Sundsfjord A, Samuelsen Ø; Norwegian Study Group of Acinetobacter. Species identification and molecular characterization of Acinetobacter spp. blood culture isolates from Norway. J Antimicrob Chemother 2011;66(4):738-744

9 Chuang YC, Sheng WH, Li SY, et al. Influence of genospecies of Acinetobacter baumannii complex on clinical outcomes of patients with Acinetobacter bacteremia. Clin Infect Dis 2011; 52(3):352-360

10 Lee YT, Kuo SC, Yang SP, et al. Bacteremic nosocomial pneumonia caused by Acinetobacter baumannii and Acinetobacter nosocomialis: a single or two distinct clinical entities? Clin Microbiol Infect 2013;19(7):640-645

11 Freire MP, de Oliveira Garcia D, Garcia CP, et al. Bloodstream infection caused by extensively drug-resistant Acinetobacter baumannii in cancer patients: high mortality associated with delayed treatment rather than with the degree of neutropenia. Clin Microbiol Infect 2016;22(4):352-358

12 Özgür ES, Horasan ES, Karaca K, Ersöz G, Naycı Atış S, Kaya A. Ventilator-associated pneumonia due to extensive drug-resistant Acinetobacter baumannii: risk factors, clinical features, and outcomes. Am J Infect Control 2014;42(2):206-208

13 Galal YS, Youssef MR, Ibrahiem SK. Ventilator-associated pneumonia: incidence, risk factors and outcome in paediatric intensive care units at Cairo University Hospital. J Clin Diagn Res 2016; 10(6):SC06-SC11

14 Sievert DM, Ricks P, Edwards JR, et al; National Healthcare Safety Network (NHSN) Team and Participating NHSN Facilities. Antimicrobial-resistant pathogens associated with healthcare-associated infections: summary of data reported to the National Healthcare Safety Network at the Centers for Disease Control and Prevention, 2009-2010. Infect Control Hosp Epidemiol 2013; 34(1):1-14

15 Tsitsopoulos PP, Iosifidis E, Antachopoulos C, et al. Nosocomial bloodstream infections in neurosurgery: a 10-year analysis in a center with high antimicrobial drug-resistance prevalence. Acta Neurochir (Wien) 2016;158(9):1647-1654

16 Jahani-Sherafat S, Razaghi M, Rosenthal VD, et al. Device-associated infection rates and bacterial resistance in six academic teaching hospitals of Iran: Findings from the International
Nocosomial Infection Control Consortium (INICC). J Infect Public Health 2015;8(6):553-561

17 Lob SH, Hoban DJ, Sahm DF, Badal RE. Regional differences and trends in antimicrobial susceptibility of Acinetobacter baumannii. Int J Antimicrob Agents 2016;47(4):317-323

18 Gao J, Zhao X, Bao Y, et al. Antibiotic resistance and OXA-type carbapenemases-encoding genes in airborne Acinetobacter baumannii isolated from burn wards. Burns 2014;40(2):295-299

19 Öncül O, Öksüz S, Acar A, et al. Nosocomial infection characteristics in a burn intensive care unit: analysis of an eleven-year active surveillance. Burns 2014;40(5):835-841

20 Oncül O, Keskin O, Acar HV, et al. Hospital-acquired infections following the 1999 Marmara earthquake. J Hosp Infect 2002; 51(1):47-51

21 Maegele M, Gregor S, Steinhausen E, et al. The long-distance tertiary air transfer and care of tsunami victims: injury pattern and microbiological and psychological aspects. Crit Care Med 2005;33(5):1136-1140

22 Zanetti G, Blanc DS, Federli I, et al. Importation of Acinetobacter baumannii into a burn unit: a recurrent outbreak of infection associated with widespread environmental contamination. Infect Control Hosp Epidemiol 2007;28(6):723-725

23 Murray CK, Yun HC, Griffith ME, Hospenthal DR, Tong M J. Acinetobacter infection: what was the true impact during the Vietnam conflict? Clin Infect Dis 2006;43(3):383-384

24 Munoz-Price LS, Weinstein RA. Acinetobacter infection. N Engl J Med 2008;358(12):1271-1281

25 Petersen K, Cannegieter SC, van der Reijden TJ, et al. Diversity and clinical impact of Acinetobacter baumannii colonization and infection at a military medical center. J Clin Microbiol 2011;49(1): 159-166

26 Granzer H, Hagen RM, Warnke P, et al. Molecular epidemiology of Carbapenem-resistant Acinetobacter Baumannii complex isolates from patients that were injured during the eastern Ukrainian conflict. Eur J Microbiol Immunol (Bp) 2016;6(2):109-117

27 Tokajian S, Eisen JA, Jospin G, et al. Draft genome sequences of Acinetobacter baumannii strains harboring the blaNDM-1 gene isolated in Lebanon from civilians wounded during the Syrian Civil War. Genome Announc 2016;4(1):1678-1715

28 Christie C, Mazon D, Hierholzer W Jr, Patterson JE. Molecular heterogeneity of Acinetobacter baumannii isolates during seasonal increase in prevalence. Infect Control Hosp Epidemiol 1995;16(10):590-594

29 Dexter C, Murray GL, Paulsen IT, Peleg AY. Community-acquired Acinetobacter baumannii: clinical characteristics, epidemiology and pathogenesis. Expert Rev Anti Infect Ther 2015;13(5): 567-573

30 Leung WS, Chu CM, Tsang KY, Lo FH, Lo KF, Ho PL. Fulminant community-acquired Acinetobacter baumannii pneumonia as a distinct clinical syndrome. Chest 2006;129(1):102-109

31 Chen MZ, Hsueh PR, Lee LN, Yu CJ, Yang PC, Luh KT. Severe community-acquired pneumonia due to Acinetobacter baumannii. Chest 2001;120(4):1072-1077

32 Anstey NM, Currie BJ, Hassell M, Palmer D, Dwyer B, Seifert H. Community-acquired bacteremic Acinetobacter pneumonia in tropical Australia is caused by diverse strains of Acinetobacter baumannii, with carriage in the throat in at-risk groups. J Clin Microbiol 2002;40(2):685-686

33 Falagas ME, Karveli EA, Kelesidis I, Kelesidis T. Communityacquired Acinetobacter infections. Eur J Clin Microbiol Infect Dis 2007;26(12):857-868

34 Kempf M, Rolain JM. Emergence of resistance to carbapenems in Acinetobacter baumannii in Europe: clinical impact and therapeutic options. Int J Antimicrob Agents 2012;39(2): 105-114

35 Garnacho-Montero J, Gutiérrez-Pizarraya A, Díaz-Martín A, et al. Acinetobacter baumannii in critically ill patients: molecular 
epidemiology, clinical features and predictors of mortality. Enferm Infecc Microbiol Clin 2016;34(9):551-558

36 Brotfain E, Borer A, Koyfman L, et al. Multidrug resistance Acinetobacter bacteremia secondary to ventilator-associated pneumonia: risk factors and outcome. J Intensive Care Med 2016:0885066616632193

37 Henig O, Weber G, Hoshen MB, et al. Risk factors for and impact of carbapenem-resistant Acinetobacter baumannii colonization and infection: matched case-control study. Eur J Clin Microbiol Infect Dis 2015;34(10):2063-2068

38 Vincent JL, Rello J, Marshall J, et al; EPIC II Group of Investigators. International study of the prevalence and outcomes of infection in intensive care units. JAMA 2009;302(21):2323-2329

39 Esterly JS, Griffith M, Qi C, Malczynski M, Postelnick MJ, Scheetz $\mathrm{MH}$. Impact of carbapenem resistance and receipt of active antimicrobial therapy on clinical outcomes of Acinetobacter baumannii bloodstream infections. Antimicrob Agents Chemother 2011;55(10):4844-4849

40 Zilberberg MD, Nathanson BH, Sulham K, Fan W, Shorr AF. Multidrug resistance, inappropriate empiric therapy, and hospital mortality in Acinetobacter baumannii pneumonia and sepsis. Crit Care 2016;20(1):221

41 Tal-Jasper R, Katz DE, Amrami N, et al. Clinical and epidemiological significance of Carbapenem resistance in Acinetobacter baumannii infections. Antimicrob Agents Chemother 2016;60(5): 3127-3131

42 Teo J, Lim TP, Hsu LY, et al. Extensively drug-resistant Acinetobacter baumannii in a Thai hospital: a molecular epidemiologic analysis and identification of bactericidal Polymyxin B-based combinations. Antimicrob Resist Infect Control 2015;4(1):2

43 Garnacho-Montero J, Dimopoulos G, Poulakou G, et al; European Society of Intensive Care Medicine. Task force on management and prevention of Acinetobacter baumannii infections in the ICU. Intensive Care Med 2015;41(12):2057-2075

44 Sader HS, Farrell DJ, Flamm RK, Jones RN. Antimicrobial susceptibility of Gram-negative organisms isolated from patients hospitalized in intensive care units in United States and European hospitals (2009-2011). Diagn Microbiol Infect Dis 2014;78(4): 443-448

45 Martins AF, Kuchenbecker R, Sukiennik T, et al. Carbapenemresistant Acinetobacter baumannii producing the OXA-23 enzyme: dissemination in Southern Brazil. Infection 2009;37(5): 474-476

46 Viana GF, Zago MC, Moreira RR, et al. ISAba1/blaOXA-23: a serious obstacle to controlling the spread and treatment of Acinetobacter baumannii strains. Am J Infect Control 2016; 44(5):593-595

47 Chung DR, Song JH, Kim SH, et al; Asian Network for Surveillance of Resistant Pathogens Study Group. High prevalence of multidrug-resistant nonfermenters in hospital-acquired pneumonia in Asia. Am J Respir Crit Care Med 2011;184(12):1409-1417

48 Kim T, Chong YP, Park SY, et al. Risk factors for hospital-acquired pneumonia caused by carbapenem-resistant Gram-negative bacteria in critically ill patients: a multicenter study in Korea. Diagn Microbiol Infect Dis 2014;78(4):457-461

49 Le NK, Hf W, Vu PD, et al. High prevalence of hospital-acquired infections caused by gram-negative carbapenem resistant strains in Vietnamese pediatric ICUs: A multi-centre point prevalence survey. Medicine (Baltimore) 2016;95(27):e4099

50 Hidron AI, Edwards JR, Patel J, et al; National Healthcare Safety Network Team; Participating National Healthcare Safety Network Facilities.NHSN annual update: antimicrobial-resistant pathogens associated with healthcare-associated infections: annual summary of data reported to the National Healthcare Safety Network at the Centers for Disease Control and Prevention, 2006-2007. Infect Control Hosp Epidemiol 2008;29(11):996-1011

51 Koulenti D, Blot S, Dulhunty JM, et al; EU-VAP/CAP Study Group. COPD patients with ventilator-associated pneumonia: implica- tions for management. Eur J Clin Microbiol Infect Dis 2015;34(12):2403-2411

52 Inchai J, Pothirat C, Liwsrisakun C, Deesomchok A, Kositsakulchai W, Chalermpanchai N. Ventilator-associated pneumonia: epidemiology and prognostic indicators of 30-day mortality. Jpn J Infect Dis 2015;68(3):181-186

53 Resende MM, Monteiro SG, Callegari B, Figueiredo PM, Monteiro CR, Monteiro-Neto V. Epidemiology and outcomes of ventilator-associated pneumonia in northern Brazil: an analytical descriptive prospective cohort study. BMC Infect Dis 2013; 13:119

54 Leblebicioglu H, Rosenthal VD, Arikan OA, et al; Turkish Branch of INICC; Findings of the International Nosocomial Infection Control Consortium (INICC). Device-associated hospital-acquired infection rates in Turkish intensive care units. J Hosp Infect 2007;65(3):251-257

55 Gaynes R, Edwards JR; National Nosocomial Infections Surveillance System. Overview of nosocomial infections caused by gram-negative bacilli. Clin Infect Dis 2005;41(6):848-854

56 Koulenti D, Tsigou E, Rello J. Nosocomial pneumonia in 27 ICUs in Europe: perspectives from the EU-VAP/CAP study. Eur J Clin Microbiol Infect Dis 2016

57 Huang ST, Chiang MC, Kuo SC, et al. Risk factors and clinical outcomes of patients with carbapenem-resistant Acinetobacter baumannii bacteremia. J Microbiol Immunol Infect 2012;45(5): 356-362

58 Trouillet JL, Chastre J, Vuagnat A, et al. Ventilator-associated pneumonia caused by potentially drug-resistant bacteria. Am J Respir Crit Care Med 1998;157(2):531-539

59 Nseir S, Blazejewski C, Lubret R, Wallet F, Courcol R, Durocher A. Risk of acquiring multidrug-resistant Gram-negative bacilli from prior room occupants in the intensive care unit. Clin Microbiol Infect 2011;17(8):1201-1208

60 Lin CY, Chen YM, Lin MC, et al. Risk factors of multidrug-resistant Acinetobacter baumannii recurrence after successful eradication in ventilated patients. Biomed J 2016;39(2):130-138

61 Apisarnthanarak A, Apisarnthanarak P, Warren DK, Fraser VJ. Is central venous catheter tips' colonization with multi-drug resistant Acinetobacter baumannii a predictor for bacteremia? Clin Infect Dis 2011;52(8):1080-1082

62 Turkoglu M, Mirza E, Tunçcan OG, et al. Acinetobacter baumannii infection in patients with hematologic malignancies in intensive care unit: risk factors and impact on mortality. J Crit Care 2011; 26(5):460-467

63 Chiang MC, Kuo SC, Chen SJ, et al. Clinical characteristics and outcomes of bacteremia due to different genomic species of Acinetobacter baumannii complex in patients with solid tumors. Infection 2012;40(1):19-26

64 Fukuta Y, Muder RR, Agha ME, et al. Risk factors for acquisition of multidrug-resistant Acinetobacter baumannii among cancer patients. Am J Infect Control 2013;41(12):1249-1252

65 Hsu JF, Chu SM, Lien R, et al. Case-control analysis of endemic Acinetobacter baumannii bacteremia in the neonatal intensive care unit. Am J Infect Control 2014;42(1):23-27

66 Gavaldà L, Soriano AM, Cámara J, et al. Control of endemic extensively drug-resistant Acinetobacter baumannii with a cohorting policy and cleaning procedures based on the 1 room, 1 wipe approach. Am J Infect Control 2016;44(5):520-524

67 Young LS, Sabel AL, Price CS. Epidemiologic, clinical, and economic evaluation of an outbreak of clonal multidrug-resistant Acinetobacter baumannii infection in a surgical intensive care unit. Infect Control Hosp Epidemiol 2007;28(11): $1247-1254$

68 Leangapichart T, Gautret P, Griffiths K, et al. Acquisition of a high diversity of bacteria during the Hajj pilgrimage, including Acinetobacter baumannii with blaOXA-72 and Escherichia coli with blaNDM-5 Carbapenemase genes. Antimicrob Agents Chemother 2016;60(10):5942-5948 
69 Peleg AY, de Breij A, Adams MD, et al. The success of Acinetobacter species; genetic, metabolic and virulence attributes. PLoS One 2012;7(10):e46984

70 Potron A, Poirel L, Nordmann P. Emerging broad-spectrum resistance in Pseudomonas aeruginosa and Acinetobacter baumannii: mechanisms and epidemiology. Int J Antimicrob Agents 2015;45(6):568-585

71 Liou ML, Soo PC, Ling SR, Kuo HY, Tang CY, Chang KC. The sensor kinase BfmS mediates virulence in Acinetobacter baumannii. J Microbiol Immunol Infect 2014;47(4):275-281

72 Dortet L, Poirel L, Nordmann P. Worldwide dissemination of the NDM-type carbapenemases in Gram-negative bacteria. BioMed Res Int 2014;2014:249856

73 Antunes LC, Visca P, Towner KJ. Acinetobacter baumannii: evolution of a global pathogen. Pathog Dis 2014;71(3):292-301

74 Pagano M, Martins AF, Barth AL. Mobile genetic elements related to carbapenem resistance in Acinetobacter baumannii. Braz J Microbiol 2016;47(4):785-792

75 Nordmann P, Poirel L, Walsh TR, Livermore DM. The emerging NDM carbapenemases. Trends Microbiol 2011;19(12):588-595

76 Gales AC, Pfaller MA, Sader HS, Hollis RJ, Jones RN. Genotypic characterization of carbapenem-nonsusceptible Acinetobacter spp. isolated in Latin America. Microb Drug Resist 2004;10(4): 286-291

77 Perez F, Endimiani A, Ray AJ, et al. Carbapenem-resistant Acinetobacter baumannii and Klebsiella pneumoniae across a hospital system: impact of post-acute care facilities on dissemination. J Antimicrob Chemother 2010;65(8):1807-1818

78 Perez F, Hujer AM, Hulten EA, et al. Antibiotic resistance determinants in Acinetobacter spp and clinical outcomes in patients from a major military treatment facility. Am J Infect Control 2010;38(1):63-65

79 Nemec A, Dijkshoorn L, van der Reijden TJ. Long-term predominance of two pan-European clones among multi-resistant Acinetobacter baumannii strains in the Czech Republic. J Med Microbiol 2004;53(Pt 2):147-153

80 Vahaboglu H, Oztürk R, Aygün G, et al. Widespread detection of PER-1-type extended-spectrum beta-lactamases among nosocomial Acinetobacter and Pseudomonas aeruginosa isolates in Turkey: a nationwide multicenter study. Antimicrob Agents Chemother 1997;41(10):2265-2269

81 Woodford N, Turton JF, Livermore DM. Multiresistant Gramnegative bacteria: the role of high-risk clones in the dissemination of antibiotic resistance. FEMS Microbiol Rev 2011;35(5): 736-755

82 Go ES, Urban C, Burns J, et al. Clinical and molecular epidemiology of Acinetobacter infections sensitive only to polymyxin B and sulbactam. Lancet 1994;344(8933):1329-1332

83 Manikal VM, Landman D, Saurina G, Oydna E, Lal H, Quale J. Endemic carbapenem-resistant Acinetobacter species in Brooklyn, New York: citywide prevalence, interinstitutional spread, and relation to antibiotic usage. Clin Infect Dis 2000;31(1): 101-106

84 Lee SO, Kim NJ, Choi SH, et al. Risk factors for acquisition of imipenem-resistant Acinetobacter baumannii: a case-control study. Antimicrob Agents Chemother 2004;48(1):224-228

85 Poirel L, Nordmann P. Carbapenem resistance in Acinetobacter baumannii: mechanisms and epidemiology. Clin Microbiol Infect 2006;12(9):826-836

86 Mathlouthi N, Al-Bayssari C, Bakour S, Rolain JM, Chouchani C. Prevalence and emergence of carbapenemases-producing Gramnegative bacteria in Mediterranean basin. Crit Rev Microbiol 2017;43(1):43-61

87 Bush K, Jacoby GA. Updated functional classification of betalactamases. Antimicrob Agents Chemother 2010;54(3):969-976

88 Mehrad B, Clark NM, Zhanel GG, Lynch JP III. Antimicrobial resistance in hospital-acquired gram-negative bacterial infections. Chest 2015;147(5):1413-1421
89 Chong Y, Ito Y, Kamimura T. Genetic evolution and clinical impact in extended-spectrum $\beta$-lactamase-producing Escherichia coli and Klebsiella pneumoniae. Infect Genet Evol 2011; 11(7):1499-1504

90 Livermore DM, Canton R, Gniadkowski M, et al. CTX-M: changing the face of ESBLs in Europe. J Antimicrob Chemother 2007;59(2): 165-174

91 Lynch JP III, Clark NM, Zhanel GG. Evolution of antimicrobial resistance among Enterobacteriaceae (focus on extended spectrum $\beta$-lactamases and carbapenemases). Expert Opin Pharmacother 2013;14(2):199-210

92 Poirel L, Karim A, Mercat A, et al. Extended-spectrum betalactamase-producing strain of Acinetobacter baumannii isolated from a patient in France. J Antimicrob Chemother 1999;43(1): 157-158

93 Naas T, Coignard B, Carbonne A, et al; French Nosocomial Infection Early Warning Investigation and Surveillance Network. VEB-1 Extended-spectrum beta-lactamase-producing Acinetobacter baumannii, France. Emerg Infect Dis 2006;12(8): 1214-1222

94 Naas T, Bogaerts P, Bauraing C, Degheldre Y, Glupczynski Y, Nordmann P. Emergence of PER and VEB extended-spectrum beta-lactamases in Acinetobacter baumannii in Belgium. J Antimicrob Chemother 2006;58(1):178-182

95 Pasterán F, Rapoport M, Petroni A, et al. Emergence of PER-2 and VEB-1a in Acinetobacter baumannii Strains in the Americas. Antimicrob Agents Chemother 2006;50(9):3222-3224

96 Shakil S, Khan AU. Detection of CTX-M-15-producing and carbapenem-resistant Acinetobacter baumannii strains from urine from an Indian hospital. J Chemother 2010;22(5):324-327

97 Potron A, Munoz-Price LS, Nordmann P, Cleary T, Poirel L. Genetic features of CTX-M-15-producing Acinetobacter baumannii from Haiti. Antimicrob Agents Chemother 2011;55(12):5946-5948

98 Zago MC, Viana GF, Ecker AB, et al. First report of CTX-M-15producing Acinetobacter baumannii in Brazil. J Hosp Infect 2016; 92(3):298-299

99 Bonnin RA, Nordmann P, Potron A, Lecuyer H, Zahar JR, Poirel L. Carbapenem-hydrolyzing GES-type extended-spectrum betalactamase in Acinetobacter baumannii. Antimicrob Agents Chemother 2011;55(1):349-354

100 Bogaerts P, Naas T, El Garch F, et al. GES extended-spectrum $\beta$-lactamases in Acinetobacter baumannii isolates in Belgium. Antimicrob Agents Chemother 2010;54(11):4872-4878

101 Chihi H, Bonnin RA, Bourouis A, et al. GES-11-producing Acinetobacter baumannii clinical isolates from Tunisian hospitals: long-term dissemination of GES-type carbapenemases in North Africa. J Glob Antimicrob Resist 2016;5:47-50

102 Charfi-Kessis K, Mansour W, Ben Haj Khalifa A, et al. Multidrugresistant Acinetobacter baumannii strains carrying the bla (OxA-23) and the bla(GES-11) genes in a neonatology center in Tunisia. Microb Pathog 2014;74:20-24

103 Yong D, Toleman MA, Giske CG, et al. Characterization of a new metallo-beta-lactamase gene, bla(NDM-1), and a novel erythromycin esterase gene carried on a unique genetic structure in Klebsiella pneumoniae sequence type 14 from India. Antimicrob Agents Chemother 2009;53(12):5046-5054

104 Berrazeg M, Diene S, Medjahed L, et al. New Delhi Metallo-betalactamase around the world: an eReview using Google Maps. Euro Surveill 2014;19(20):20809

105 Poirel L, Marqué S, Héritier C, Segonds C, Chabanon G, Nordmann P. OXA-58, a novel class D beta-lactamase involved in resistance to carbapenems in Acinetobacter baumannii. Antimicrob Agents Chemother 2005;49(1):202-208

106 Rodríguez CH, Balderrama Yarhui N, Nastro M, et al. Molecular epidemiology of carbapenem-resistant Acinetobacter baumannii in South America. J Med Microbiol 2016;65(10):1088-1091

107 Pagano M, Barin J, Martins AF, Zavascki AP. High endemic rates of OXA-23-producing carbapenem-resistant Acinetobacter 
baumannii isolates caused by the persistence of major clones in hospitals in a Brazilian city 5 years after an outbreak. Infect Control Hosp Epidemiol 2015;36(7):860-862

108 Paton R, Miles RS, Hood J, Amyes SG, Miles RS, Amyes SG. ARI 1: beta-lactamase-mediated imipenem resistance in Acinetobacter baumannii. Int J Antimicrob Agents 1993;2(2):81-87

109 Dias VC, Diniz CG, Peter AC, et al. Epidemiological characteristics and antimicrobial susceptibility among carbapenem-resistant non-fermenting bacteria in Brazil. J Infect Dev Ctries 2016;10(6): 544-553

110 Coelho JM, Turton JF, Kaufmann ME, et al. Occurrence of carbapenem-resistant Acinetobacter baumannii clones at multiple hospitals in London and Southeast England. J Clin Microbiol 2006;44(10):3623-3627

111 Wareham DW, Bean DC, Khanna P, et al. Bloodstream infection due to Acinetobacter spp: epidemiology, risk factors and impact of multi-drug resistance. Eur J Clin Microbiol Infect Dis 2008; 27(7):607-612

112 Xu A, Zheng B, Xu YC, Huang ZG, Zhong NS, Zhuo C. National epidemiology of carbapenem-resistant and extensively drugresistant Gram-negative bacteria isolated from blood samples in China in 2013. Clin Microbiol Infect 2016;22(Suppl 1):S1-S8

113 Fu Y, Jiang J, Zhou H, et al. Characterization of a novel plasmid type and various genetic contexts of bla OXA-58 in Acinetobacter spp. from multiple cities in China. PLoS One 2014;9(1):e84680

114 Merino M, Poza M, Roca I, et al. Nosocomial outbreak of a multiresistant Acinetobacter baumannii expressing OXA-23 carbapenemase in Spain. Microb Drug Resist 2014;20(4):259-263

115 Adams-Haduch JM, Onuoha EO, Bogdanovich T, et al. Molecular epidemiology of carbapenem-nonsusceptible Acinetobacter baumannii in the United States. J Clin Microbiol 2011;49(11): 3849-3854

116 Mezzatesta ML, Caio C, Gona F, et al. Carbapenem and multidrug resistance in Gram-negative bacteria in a single centre in Italy: considerations on in vitro assay of active drugs. Int J Antimicrob Agents 2014;44(2):112-116

117 Yigit H, Queenan AM, Anderson GJ, et al. Novel carbapenemhydrolyzing beta-lactamase, KPC-1, from a carbapenem-resistant strain of Klebsiella pneumoniae. Antimicrob Agents Chemother 2001;45(4):1151-1161

118 Bradford PA, Bratu S, Urban C, et al. Emergence of carbapenemresistant Klebsiella species possessing the class A carbapenemhydrolyzing KPC-2 and inhibitor-resistant TEM-30 beta-lactamases in New York City. Clin Infect Dis 2004;39(1):55-60

119 Naas T, Nordmann P, Vedel G, Poyart C. Plasmid-mediated carbapenem-hydrolyzing beta-lactamase KPC in a Klebsiella pneumoniae isolate from France. Antimicrob Agents Chemother 2005;49(10):4423-4424

120 Baraniak A, Izdebski R, Fiett J, et al; MOSAR WP2, WP3, and WP5 Study Groups. KPC-like carbapenemase-producing Enterobacteriaceae colonizing patients in Europe and Israel. Antimicrob Agents Chemother 2015;60(3):1912-1917

121 Martinez T, Martinez I, Vazquez GJ, Aquino EE, Robledo IE. Genetic environment of the KPC gene in Acinetobacter baumannii ST2 clone from Puerto Rico and genomic insights into its drug resistance. J Med Microbiol 2016;65(8):784-792

122 Robledo IE, Aquino EE, Santé MI, et al. Detection of KPC in Acinetobacter spp. in Puerto Rico. Antimicrob Agents Chemother 2010;54(3):1354-1357

123 Moubareck C, Brémont S, Conroy MC, Courvalin P, Lambert T. GES-11, a novel integron-associated GES variant in Acinetobacter baumannii. Antimicrob Agents Chemother 2009;53(8): 3579-3581

124 Bonnin RA, Rotimi VO, Al Hubail M, et al. Wide dissemination of GES-type carbapenemases in Acinetobacter baumannii isolates in Kuwait. Antimicrob Agents Chemother 2013;57(1):183-188

125 Cicek AC, Saral A, Iraz M, et al. OXA- and GES-type $\beta$-lactamases predominate in extensively drug-resistant Acinetobacter bau- mannii isolates from a Turkish University Hospital. Clin Microbiol Infect 2014;20(5):410-415

126 Bonnin RA, Poirel L, Naas T, et al. Dissemination of New Delhi metallo- $\beta$-lactamase-1-producing Acinetobacter baumannii in Europe. Clin Microbiol Infect 2012;18(9):E362-E365

127 Castanheira M, Deshpande LM, Mathai D, Bell JM, Jones RN Mendes RE. Early dissemination of NDM-1- and OXA-181producing Enterobacteriaceae in Indian hospitals: report from the SENTRY Antimicrobial Surveillance Program, 2006-2007. Antimicrob Agents Chemother 2011;55(3): $1274-1278$

128 Moellering RC Jr. NDM-1-a cause for worldwide concern. N Engl J Med 2010;363(25):2377-2379

129 Centers for Disease Control and Prevention (CDC). Detection of Enterobacteriaceae isolates carrying metallo-beta-lactamase United States, 2010. MMWR Morb Mortal Wkly Rep 2010;59(24):750

130 Poirel L, Hombrouck-Alet C, Freneaux C, Bernabeu S, Nordmann P. Global spread of New Delhi metallo- $\beta$-lactamase 1. Lancet Infect Dis 2010;10(12):832

131 Poirel L, Bonnin RA, Boulanger A, Schrenzel J, Kaase M, Nordmann P. Tn125-related acquisition of blaNDM-like genes in Acinetobacter baumannii. Antimicrob Agents Chemother 2012; 56(2):1087-1089

132 Hammerum AM, Larsen AR, Hansen F, et al. Patients transferred from Libya to Denmark carried OXA-48-producing Klebsiella pneumoniae, NDM-1-producing Acinetobacter baumannii and meticillin-resistant Staphylococcus aureus. Int J Antimicrob Agents 2012;40(2):191-192

133 El-Sayed-Ahmed MA, Amin MA, Tawakol WM, Loucif L, Bakour S, Rolain JM. High prevalence of bla(NDM-1) carbapenemase-encoding gene and 16S rRNA armA methyltransferase gene among Acinetobacter baumannii clinical Isolates in Egypt. Antimicrob Agents Chemother 2015;59(6):3602-3605

134 Pfeifer Y, Wilharm G, Zander E, et al. Molecular characterization of blaNDM-1 in an Acinetobacter baumannii strain isolated in Germany in 2007. J Antimicrob Chemother 2011;66(9): 1998-2001

135 Ghazawi A, Sonnevend A, Bonnin RA, et al. NDM-2 carbapenemase-producing Acinetobacter baumannii in the United Arab Emirates. Clin Microbiol Infect 2012;18(2):E34-E36

136 Espinal P, Fugazza G, López Y, et al. Dissemination of an NDM2-producing Acinetobacter baumannii clone in an Israeli rehabilitation center. Antimicrob Agents Chemother 2011;55(11): 5396-5398

137 El-Herte RI, Kanj SS, Matar GM, Araj GF. The threat of carbapenem-resistant Enterobacteriaceae in Lebanon: an update on the regional and local epidemiology. J Infect Public Health 2012; 5(3):233-243

138 Kaase M, Nordmann P, Wichelhaus TA, Gatermann SG, Bonnin RA, Poirel L. NDM-2 carbapenemase in Acinetobacter baumannii from Egypt. J Antimicrob Chemother 2011;66(6):1260-1262

139 Bonnin RA, Poirel L, Nordmann P. New Delhi metallo- $\beta$-lactamase-producing Acinetobacter baumannii: a novel paradigm for spreading antibiotic resistance genes. Future Microbiol 2014; 9(1):33-41

140 Khorsi K, Messai Y, Hamidi M, Ammari H, Bakour R. High prevalence of multidrug-resistance in Acinetobacter baumannii and dissemination of carbapenemase-encoding genes blaOXA23-like, blaOXA-24-like and blaNDM-1 in Algiers hospitals. Asian Pac J Trop Med 2015;8(6):438-446

141 Mathlouthi N, El Salabi AA, Ben Jomàa-Jemili M, et al. Early detection of metallo- $\beta$-lactamase NDM-1- and OXA-23 carbapenemase-producing Acinetobacter baumannii in Libyan hospitals. Int J Antimicrob Agents 2016;48(1):46-50

142 Decousser JW, Jansen C, Nordmann P, et al. Outbreak of NDM1-producing Acinetobacter baumannii in France, January to May 2013. Euro Surveill 2013;18(31):20547 
143 Boulanger A, Naas T, Fortineau N, Figueiredo S, Nordmann P. NDM-1-producing Acinetobacter baumannii from Algeria. Antimicrob Agents Chemother 2012;56(4):2214-2215

144 Poirel L, Revathi G, Bernabeu S, Nordmann P. Detection of NDM1-producing Klebsiella pneumoniae in Kenya. Antimicrob Agents Chemother 2011;55(2):934-936

145 Zhang R, Hu YY, Yang XF, et al. Emergence of NDM-producing non-baumannii Acinetobacter spp. isolated from China. Eur J Clin Microbiol Infect Dis 2014;33(5):853-860

146 Huang YM, Zhong LL, Zhang XF, et al. NDM-1-Producing Citrobacter freundii, Escherichia coli, and Acinetobacter baumannii Identified from a Single Patient in China. Antimicrob Agents Chemother 2015;59(8):5073-5077

147 Nakazawa Y, Ii R, Tamura T, et al. A case of NDM-1-producing Acinetobacter baumannii transferred from India to Japan. J Infect Chemother 2013;19(2):330-332

148 Chen Y, Zhou Z, Jiang Y, Yu Y. Emergence of NDM-1-producing Acinetobacter baumannii in China. J Antimicrob Chemother 2011;66(6):1255-1259

149 Yang J, Chen Y, Jia X, et al. Dissemination and characterization of NDM-1-producing Acinetobacter pittii in an intensive care unit in China. Clin Microbiol Infect 2012;18(12):E506-E513

150 Pagano M, Poirel L, Martins AF, et al. Emergence of NDM1-producing Acinetobacter pittii in Brazil. Int J Antimicrob Agents 2015;45(4):444-445

151 Pasteran F, Mora MM, Albornoz E, et al. Emergence of genetically unrelated NDM-1-producing Acinetobacter pittii strains in Paraguay. J Antimicrob Chemother 2014;69(9):2575-2578

152 Montaña S, Cittadini R, Del Castillo M, et al. Presence of New Delhi metallo- $\beta$-lactamase gene (NDM-1) in a clinical isolate of Acinetobacter junii in Argentina. New Microbes New Infect 2016; 11:43-44

153 Waterman PE, McGann P, Snesrud E, et al. Bacterial peritonitis due to Acinetobacter baumannii sequence type 25 with plasmidborne New Delhi metallo- $\beta$-lactamase in Honduras. Antimicrob Agents Chemother 2013;57(9):4584-4586

154 Kim Y, Bae IK, Lee H, Jeong SH, Yong D, Lee K. In vivo emergence of colistin resistance in Acinetobacter baumannii clinical isolates of sequence type 357 during colistin treatment. Diagn Microbiol Infect Dis 2014;79(3):362-366

155 Cai Y, Chai D, Wang R, Liang B, Bai N. Colistin resistance of Acinetobacter baumannii: clinical reports, mechanisms and antimicrobial strategies. J Antimicrob Chemother 2012;67(7): 1607-1615

156 Rhomberg PR, Jones RN. Summary trends for the Meropenem Yearly Susceptibility Test Information Collection Program: a 10year experience in the United States (1999-2008). Diagn Microbiol Infect Dis 2009;65(4):414-426

157 Mera RM, Miller LA, Amrine-Madsen H, Sahm DF. Acinetobacter baumannii 2002-2008: increase of carbapenem-associated multiclass resistance in the United States. Microb Drug Resist 2010; 16(3):209-215

158 Denys GA, Callister SM, Dowzicky MJ. Antimicrobial susceptibility among gram-negative isolates collected in the USA between 2005 and 2011 as part of the Tigecycline Evaluation and Surveillance Trial (T.E.S.T.). Ann Clin Microbiol Antimicrob 2013;12:24

159 Queenan AM, Pillar CM, Deane J, et al. Multidrug resistance among Acinetobacter spp. in the USA and activity profile of key agents: results from CAPITAL Surveillance 2010. Diagn Microbiol Infect Dis 2012;73(3):267-270

160 Jones RN, Guzman-Blanco M, Gales AC, et al. Susceptibility rates in Latin American nations: report from a regional resistance surveillance program (2011). Braz J Infect Dis 2013;17(6):672-681

161 Lee MH, Chen TL, Lee YT, et al. Dissemination of multidrugresistant Acinetobacter baumannii carrying BlaOxA-23 from hospitals in central Taiwan. J Microbiol Immunol Infect 2013; 46(6):419-424
162 Lee HS, Loh YX, Lee JJ, Liu CS, Chu C. Antimicrobial consumption and resistance in five Gram-negative bacterial species in a hospital from 2003 to 2011. J Microbiol Immunol Infect 2015; 48(6):647-654

163 Nordmann P, Picazo JJ, Mutters R, et al; COMPACT study group. Comparative activity of carbapenem testing: the COMPACT study. J Antimicrob Chemother 2011;66(5):1070-1078

164 Turner PJ. Meropenem activity against European isolates: report on the MYSTIC (Meropenem Yearly Susceptibility Test Information Collection) 2006 results. Diagn Microbiol Infect Dis 2008; 60(2):185-192

165 Gales AC, Jones RN, Sader HS. Contemporary activity of colistin and polymyxin $B$ against a worldwide collection of Gram-negative pathogens: results from the SENTRY Antimicrobial Surveillance Program (2006-09). J Antimicrob Chemother 2011;66(9): 2070-2074

166 Kuo SC, Lee YT, Yang SP, et al. Evaluation of the effect of appropriate antimicrobial therapy on mortality associated with Acinetobacter nosocomialis bacteraemia. Clin Microbiol Infect 2013;19(7):634-639

167 Ogutlu A, Guclu E, Karabay O, Utku AC, Tuna N, Yahyaoglu M. Effects of Carbapenem consumption on the prevalence of Acinetobacter infection in intensive care unit patients. Ann Clin Microbiol Antimicrob 2014;13:7

168 Oliveira MS, Prado GV, Costa SF, Grinbaum RS, Levin AS. Ampicillin/sulbactam compared with polymyxins for the treatment of infections caused by carbapenem-resistant Acinetobacter spp. J Antimicrob Chemother 2008;61(6):1369-1375

169 Jaruratanasirikul S, Wongpoowarak W, Aeinlang N, Jullangkoon M. Pharmacodynamics modeling to optimize dosage regimens of sulbactam. Antimicrob Agents Chemother 2013;57(7): 3441-3444

170 Betrosian AP, Frantzeskaki F, Xanthaki A, Douzinas EE. Efficacy and safety of high-dose ampicillin/sulbactam vs. colistin as monotherapy for the treatment of multidrug resistant Acinetobacter baumannii ventilator-associated pneumonia. J Infect 2008;56(6):432-436

171 Laishram S, Anandan S, Devi BY, et al. Determination of synergy between sulbactam, meropenem and colistin in carbapenemresistant Klebsiella pneumoniae and Acinetobacter baumannii isolates and correlation with the molecular mechanism of resistance. J Chemother 2016;28(4):297-303

172 Buisson Y, Tran Van Nhieu G, Ginot L, et al. Nosocomial outbreaks due to amikacin-resistant tobramycin-sensitive Acinetobacter species: correlation with amikacin usage. J Hosp Infect 1990; 15(1):83-93

173 Lesho E, Chukwuma U, Sparks M, et al. Anatomic, geographic, and taxon-specific relative risks of carbapenem resistance in the health care system of the U.S. Department of Defense. J Clin Microbiol 2016;54(6):1546-1551

174 Lesho EP, Waterman PE, Chukwuma U, et al. The antimicrobial resistance monitoring and research (ARMoR) program: the US Department of Defense response to escalating antimicrobial resistance. Clin Infect Dis 2014;59(3):390-397

175 Göttig S, Gruber TM, Higgins PG, Wachsmuth M, Seifert H, Kempf VA. Detection of pan drug-resistant Acinetobacter baumannii in Germany. J Antimicrob Chemother 2014;69(9):2578-2579

176 Pogue JM, Lee J, Marchaim D, et al. Incidence of and risk factors for colistin-associated nephrotoxicity in a large academic health system. Clin Infect Dis 2011;53(9):879-884

177 Leporati M, Bua RO, Mariano F, et al. Determination by LC-MS/MS of colistins A and B in plasma and ultrafiltrate from critically ill patients undergoing continuous venovenous hemodiafiltration. Ther Drug Monit 2014;36(2):182-191

178 De Pascale G, Montini L, Pennisi M, et al. High dose tigecycline in critically ill patients with severe infections due to multidrugresistant bacteria. Crit Care 2014;18(3):R90 
179 Rao GG, Ly NS, Bulitta JB, et al. Polymyxin B in combination with doripenem against heteroresistant Acinetobacter baumannii: pharmacodynamics of new dosing strategies. J Antimicrob Chemother 2016;71(11):3148-3156

180 Cheah SE, Li J, Tsuji BT, Forrest A, Bulitta JB, Nation RL. Colistin and polymyxin B dosage regimens against Acinetobacter baumannii: differences in activity and the emergence of resistance. Antimicrob Agents Chemother 2016;60(7):3921-3933

181 Cheah SE, Johnson MD, Zhu Y, et al. Polymyxin resistance in Acinetobacter baumannii: genetic mutations and transcriptomic changes in response to clinically relevant dosage regimens. Sci Rep 2016;6:26233

182 Garnacho J, Sole-Violan J, Sa-Borges M, Diaz E, Rello J. Clinical impact of pneumonia caused by Acinetobacter baumannii in intubated patients: a matched cohort study. Crit Care Med 2003;31(10):2478-2482

183 Batirel A, Balkan II, Karabay O, et al. Comparison of colistincarbapenem, colistin-sulbactam, and colistin plus other antibacterial agents for the treatment of extremely drug-resistant Acinetobacter baumannii bloodstream infections. Eur J Clin Microbiol Infect Dis 2014;33(8):1311-1322

184 López-Cortés LE, Cisneros JM, Fernández-Cuenca F, et al; GEIH/ REIPI-Ab2010 Group. Monotherapy versus combination therapy for sepsis due to multidrug-resistant Acinetobacter baumannii: analysis of a multicentre prospective cohort. J Antimicrob Chemother 2014;69(11):3119-3126

185 Shields RK, Clancy CJ, Gillis LM, et al. Epidemiology, clinical characteristics and outcomes of extensively drug-resistant Acinetobacter baumannii infections among solid organ transplant recipients. PLoS One 2012;7(12):e52349

186 Chen YM, Fang WF, Kao HC, et al. Influencing factors of successful eradication of multidrug-resistant Acinetobacter baumannii in the respiratory tract with aerosolized colistin. Biomed J 2014; 37(5):314-320

187 Liu YY, Wang Y, Walsh TR, et al. Emergence of plasmid-mediated colistin resistance mechanism MCR-1 in animals and human beings in China: a microbiological and molecular biological study. Lancet Infect Dis 2016;16(2):161-168

188 Poirel L, Kieffer N, Liassine N, Thanh D, Nordmann P. Plasmidmediated carbapenem and colistin resistance in a clinical isolate of Escherichia coli. Lancet Infect Dis 2016;16(3):281

189 Nordmann P, Lienhard R, Kieffer N, Clerc O, Poirel L. Plasmidmediated colistin-resistant Escherichia coli in bacteremia in Switzerland. Clin Infect Dis 2016;62(10):1322-1323

190 Payne M, Croxen MA, Lee TD, et al. mcr-1-positive colistinresistant Escherichia coli in traveler returning to Canada from China. Emerg Infect Dis 2016;22(9):1673-1675

191 Teo JW, Chew KL, Lin RT. Transmissible colistin resistance encoded by mcr-1 detected in clinical Enterobacteriaceae isolates in Singapore. Emerg Microbes Infect 2016;5(8):e87

192 Rolain JM, Roch A, Castanier M, Papazian L, Raoult D. Acinetobacter baumannii resistant to colistin with impaired virulence: a case report from France. J Infect Dis 2011;204(7): 1146-1147

193 López-Rojas R, Domínguez-Herrera J, McConnell MJ, et al. Impaired virulence and in vivo fitness of colistin-resistant Acinetobacter baumannii. J Infect Dis 2011;203(4):545-548

194 Hua X, Chen Q Li X, Yu Y. Global transcriptional response of Acinetobacter baumannii to a subinhibitory concentration of tigecycline. Int J Antimicrob Agents 2014;44(4):337-344

195 Hoban DJ, Reinert RR, Bouchillon SK, Dowzicky MJ. Global in vitro activity of tigecycline and comparator agents: Tigecycline Evaluation and Surveillance Trial 2004-2013. Ann Clin Microbiol Antimicrob 2015;14:27

196 Ku K, Pogue JM, Moshos J, et al. Retrospective evaluation of colistin versus tigecycline for the treatment of Acinetobacter baumannii and/or carbapenem-resistant Enterobacteriaceae infections. Am J Infect Control 2012;40(10):983-987
197 Lee YT, Tsao SM, Hsueh PR. Clinical outcomes of tigecycline alone or in combination with other antimicrobial agents for the treatment of patients with healthcare-associated multidrugresistant Acinetobacter baumannii infections. Eur J Clin Microbiol Infect Dis 2013;32(9):1211-1220

198 Freire AT, Melnyk V, Kim MJ, et al; 311 Study Group. Comparison of tigecycline with imipenem/cilastatin for the treatment of hospital-acquired pneumonia. Diagn Microbiol Infect Dis 2010;68(2):140-151

199 Chuang YC, Cheng CY, Sheng WH, et al. Effectiveness of tigecycline-based versus colistin- based therapy for treatment of pneumonia caused by multidrug-resistant Acinetobacter baumannii in a critical setting: a matched cohort analysis. BMC Infect Dis 2014;14:102

200 Ye JJ, Lin HS, Yeh CF, et al. Tigecycline-based versus sulbactambased treatment for pneumonia involving multidrug-resistant Acinetobacter calcoaceticus-Acinetobacter baumannii complex. BMC Infect Dis 2016;16:374

201 Prasad P, Sun J, Danner RL, Natanson C. Excess deaths associated with tigecycline after approval based on noninferiority trials. Clin Infect Dis 2012;54(12):1699-1709

202 Abdallah M, Olafisoye O, Cortes C, Urban C, Landman D, Quale J. Activity of eravacycline against Enterobacteriaceae and Acinetobacter baumannii, including multidrug-resistant isolates, from New York City. Antimicrob Agents Chemother 2015;59(3): 1802-1805

203 Livermore DM, Mushtaq S, Warner M, Woodford N. In vitro activity of eravacycline against carbapenem-resistant Enterobacteriaceae and Acinetobacter baumannii. Antimicrob Agents Chemother 2016;60(6):3840-3844

204 Aydemir H, Akduman D, Piskin N, et al. Colistin vs. the combination of colistin and rifampicin for the treatment of carbapenemresistant Acinetobacter baumannii ventilator-associated pneumonia. Epidemiol Infect 2013;141(6):1214-1222

205 Durante-Mangoni E, Signoriello G, Andini R, et al. Colistin and rifampicin compared with colistin alone for the treatment of serious infections due to extensively drug-resistant Acinetobacter baumannii: a multicenter, randomized clinical trial. Clin Infect Dis 2013;57(3):349-358

206 Cheng A, Chuang YC, Sun HY, et al. Excess mortality associated with colistin-tigecycline compared with colistin-carbapenem combination therapy for extensively drug-resistant Acinetobacter baumannii bacteremia: a multicenter prospective observational study. Crit Care Med 2015;43(6):1194-1204

207 Hong DJ, Kim JO, Lee H, et al. In vitro antimicrobial synergy of colistin with rifampicin and carbapenems against colistinresistant Acinetobacter baumannii clinical isolates. Diagn Microbiol Infect Dis 2016;86(2):184-189

208 Park GC, Choi JA, Jang SJ, et al. In vitro interactions of antibiotic combinations of colistin, tigecycline, and doripenem against extensively drug-resistant and multidrug-resistant Acinetobacter baumannii. Ann Lab Med 2016;36(2):124-130

209 Garnacho-Montero J, Amaya-Villar R, Gutiérrez-Pizarraya A, et al. Clinical efficacy and safety of the combination of colistin plus vancomycin for the treatment of severe infections caused by carbapenem-resistant Acinetobacter baumannii. Chemotherapy 2013;59(3):225-231

210 Petrosillo N, Giannella M, Antonelli M, et al. Clinical experience of colistin-glycopeptide combination in critically ill patients infected with Gram-negative bacteria. Antimicrob Agents Chemother 2014;58(2):851-858

211 Bassetti M, Ginocchio F, Mikulska M, Taramasso L, Giacobbe DR. Will new antimicrobials overcome resistance among Gramnegatives? Expert Rev Anti Infect Ther 2011;9(10):909-922

212 Syue LS, Chen YH, Ko WC, Hsueh PR. New drugs for the treatment of complicated intra-abdominal infections in the era of increasing antimicrobial resistance. Int J Antimicrob Agents 2016;47(4): 250-258 
213 Higgins PG, Stefanik D, Page MG, Hackel M, Seifert H. In vitro activity of the siderophore monosulfactam BAL30072 against meropenem-non-susceptible Acinetobacter baumannii. J Antimicrob Chemother 2012;67(5):1167-1169

214 López-Rojas R, Sánchez-Céspedes J, Docobo-Pérez F, DomínguezHerrera J, Vila J, Pachón J. Pre-clinical studies of a new quinolone (UB-8902) against Acinetobacter baumannii resistant to ciprofloxacin. Int J Antimicrob Agents 2011;38(4):355-359

215 Zhanel GG, Lawson CD, Adam H, et al. Ceftazidime-avibactam: a novel cephalosporin/ $\beta$-lactamase inhibitor combination. Drugs 2013;73(2):159-177

216 Bassetti M, Righi E. New antibiotics and antimicrobial combination therapy for the treatment of gram-negative bacterial infections. Curr Opin Crit Care 2015;21(5):402-411

217 van Duin D, Bonomo RA. Ceftazidime/Avibactam and Ceftolozane/Tazobactam: second-generation $\beta$-lactam/ $\beta$-lactamase inhibitor combinations. Clin Infect Dis 2016;63(2):234-241

218 Zhanel GG, Chung P, Adam H, et al. Ceftolozane/tazobactam: a novel cephalosporin/ $\beta$-lactamase inhibitor combination with activity against multidrug-resistant gram-negative bacilli. Drugs 2014;74(1):31-51

219 García-Salguero C, Rodríguez-Avial I, Picazo JJ, Culebras E. Can plazomicin alone or in combination be a therapeutic option against carbapenem-resistant Acinetobacter baumannii? Antimicrob Agents Chemother 2015;59(10):5959-5966

220 Zhanel GG, Lawson CD, Zelenitsky S, et al. Comparison of the next-generation aminoglycoside plazomicin to gentamicin, tobramycin and amikacin. Expert Rev Anti Infect Ther 2012; 10(4):459-473

221 Jacobs MR, Bajaksouzian S, Good CE, et al. Novel bis-indole agents active against multidrug-resistant Acinetobacter baumannii. Diagn Microbiol Infect Dis 2011;69(1):114-116
222 Trzoss M, Bensen DC, Li X, et al. Pyrrolopyrimidine inhibitors of DNA gyrase B (GyrB) and topoisomerase IV (ParE), Part II: development of inhibitors with broad spectrum, Gram-negative antibacterial activity. Bioorg Med Chem Lett 2013;23(5): 1537-1543

223 Yount NY, Yeaman MR. Peptide antimicrobials: cell wall as a bacterial target. Ann N Y Acad Sci 2013;1277:127-138

224 Vila-Farres X, Garcia de la Maria C, López-Rojas R, Pachón J, Giralt E, Vila J. In vitro activity of several antimicrobial peptides against colistin-susceptible and colistin-resistant Acinetobacter baumannii. Clin Microbiol Infect 2012;18(4):383-387

225 La Forgia C, Franke J, Hacek DM, Thomson RB Jr, Robicsek A, Peterson LR. Management of a multidrug-resistant Acinetobacter baumannii outbreak in an intensive care unit using novel environmental disinfection: a 38-month report. Am J Infect Control 2010;38(4):259-263

226 Mirhoseini SH, Nikaeen M, Shamsizadeh Z, Khanahmad H. Hospital air: A potential route for transmission of infections caused by $\beta$-lactam-resistant bacteria. Am J Infect Control 2016; 44(8):898-904

227 Munoz-Price LS, Namias N, Cleary T, et al. Acinetobacter baumannii: association between environmental contamination of patient rooms and occupant status. Infect Control Hosp Epidemiol 2013;34(5):517-520

228 Łysakowska ME, Ciebiada-Adamiec A, Klimek L, Sienkiewicz M. The activity of silver nanoparticles (Axonnite) on clinical and environmental strains of Acinetobacter spp. Burns 2015;41(2): 364-371

229 Martínez-Reséndez MF, Garza-González E, Mendoza-Olazaran S, et al. Impact of daily chlorhexidine baths and hand hygiene compliance on nosocomial infection rates in critically ill patients. Am J Infect Control 2014;42(7):713-717 